\title{
Road Performance and Emission Reduction Effect of Graphene/Tourmaline-Composite-Modified Asphalt
}

\author{
Tengteng Guo ${ }^{1}$, Hao Fu ${ }^{2}$, Chaohui Wang ${ }^{2, *}$, Haijun Chen ${ }^{1}$, Qian Chen ${ }^{2, *} \mathbb{D}$, Qing Wang ${ }^{3}$, Yuanzhao Chen ${ }^{1} \mathbb{D}$, \\ Zhenxia $\mathrm{Li}^{1}{ }^{1}$ and Aijiu Chen ${ }^{1}$ \\ 1 School of Civil Engineering and Communication, North China University of Water Resources and Electric \\ Power, Zhengzhou 450045, China; guotth@ncwu.edu.cn (T.G.); chenhaijun@ncwu.edu.cn (H.C.); \\ cyz740513@ncwu.edu.cn (Y.C.); zhenxiali2009@ncwu.edu.cn (Z.L.); caj@ncwu.edu.cn (A.C.) \\ 2 School of Highway, Chang'an University, Xi'an 710064, China; 2019021038@chd.edu.cn \\ 3 Henan College of Transportation, Zhengzhou 450015, China; wangqing@vip.tom.com \\ * Correspondence: wchh0205@chd.edu.cn (C.W.); 2016121160@chd.edu.cn (Q.C.)
}

Citation: Guo, T.; Fu, H.; Wang, C.; Chen, H.; Chen, Q.; Wang, Q.; Chen, Y.; Li, Z.; Chen, A. Road Performance and Emission Reduction Effect of Graphene/Tourmaline-CompositeModified Asphalt. Sustainability 2021, 13, 8932. https://doi.org/10.3390/ su13168932

Academic Editor: Edoardo Bocci

Received: 31 May 2021

Accepted: 5 August 2021

Published: 10 August 2021

Publisher's Note: MDPI stays neutral with regard to jurisdictional claims in published maps and institutional affiliations.

Copyright: (c) 2021 by the authors. Licensee MDPI, Basel, Switzerland. This article is an open access article distributed under the terms and conditions of the Creative Commons Attribution (CC BY) license (https:// creativecommons.org/licenses/by/ $4.0 /)$.

\begin{abstract}
The purpose of this study is to further improve the road performance and emission reduction effect of tourmaline-modified asphalt. Graphene was used to enhance the performance of tourmaline-modified asphalt, and graphene/tourmaline-composite-modified asphalt was prepared. The temperature susceptibility, high temperature, anti-aging properties and rheological performance of the modified asphalt were studied. The test method of emission reduction efficiency of the modified asphalt and its mixture was proposed. The emission reduction effect of different modified asphalts and its mixture was evaluated. The enhancement effect of graphene on the properties of tourmaline-modified asphalt was confirmed. It provides a reference for the performance enhancement of inorganic material modified asphalt. The results show that the temperature susceptibility, high temperature, anti-aging properties and rheological performance of the graphene/tourmalinecomposite-modified asphalt are better than those of the tourmaline-modified asphalt and base asphalt. The asphalt fume reduction rate of graphene/tourmaline-composite-modified asphalt is higher than that of tourmaline-modified asphalt. With the increase of graphene content, the emission reduction performance increases gradually, and the enhancement effect of graphene on tourmaline performance is more obvious.
\end{abstract}

Keywords: road materials; modified asphalt; tourmaline; asphalt fume pollution; emission reduction effect; graphene

\section{Introduction}

With the vigorous development of highway transportation, people put forward higher requirements for the service performance and quality of pavement [1-3]. Various kinds of asphalt modifiers have been widely studied and applied to improve the service quality and durability of asphalt pavement. At present, asphalt modifiers can be divided into inorganic material modifiers and polymer modifiers. Most polymer modified asphalts need to be prepared at higher temperatures, which has the disadvantages of high cost, complex equipment and preparation process [4,5]. Inorganic material modifiers can not only improve the interface between asphalt and mineral aggregate and asphalt pavement performance, but also has the characteristics of simple production process, low price, excellent performance and rich reserves. It has been more and more favored by pavement researchers [6-11].

Tourmaline is a kind of silicate mineral with piezoelectric and thermoelectric properties. It is widely used in air purification, water purification, cooling coatings and other environmental protection fields [12-15]. In recent years, some researchers have applied it to prepare modified asphalt and modified asphalt mixtures. Wang et al. studied the road performance of tourmaline-modified asphalt and its mixture as well as its effects of 
emission reduction, flame retardancy and smoke suppression. It was found that tourmaline can effectively improve the pavement performance of asphalt and has certain environmental effects [16-18]. Tourmaline can adsorb the asphalt smoke pollutants generated when the asphalt is heated, and the adsorption rate can reach more than $50 \%$. Moreover, it can also purify automobile exhaust, and has the most obvious purification effect on NOx, with a purification rate of $85.7 \%$. In addition, compared with ordinary asphalt mixture, tourmaline-modified asphalt mixture is difficult to be ignited, and the amount of smoke generated during combustion is small, which has significant flame retardant and smoke suppression functions $[19,20]$. Wu et al. studied the high temperature performance of tourmaline-modified asphalt mortar and determined the influence of the tourmaline content and mesh number on the high temperature performance of tourmaline-modified asphalt [21]. Ding et al. found that tourmaline powder can significantly improve the fatigue life of base asphalt mixture and SBS modified asphalt mixture and enhance the high temperature rutting resistance of asphalt pavement [22].

The performance optimization of tourmaline for asphalt mainly comes from its piezoelectric and thermoelectric properties. Wang et al. found that graphene can enhance the piezoelectric and thermoelectric properties of tourmaline [16]. At the same time, graphene has the advantages of a large specific surface area, high surface energy and an excellent interface effect. At present, the application of graphene in the performance enhancement of asphalt and the composite-modified asphalt preparation have been explored and studied [23-29]. Su et al. improved the surface activity of polyacrylonitrile (PAN) by covalent grafting of aminated graphene and further prepared graphene fiber asphalt. The results of a dynamic shear rheological (DSR) test showed that the viscoelasticity and permanent deformation resistance of the asphalt were significantly improved [30]. Guo et al. found that the addition of graphene can improve the elastic recovery and deformation resistance of rubber asphalt and improve its rheological properties [31]. To sum up, the current research mainly focuses on the performance evaluation of modified asphalt with only tourmaline and the modified asphalt mixture. There is a lack of studies on the performance enhancement of tourmaline-modified asphalt and the preparation of tourmaline-composite-modified asphalt. The advantages of graphene make it obtain excellent application effects in enhancing the activity of asphalt modifiers and the performance of modified asphalt. However, there are few studies on the performance evaluation of graphene-reinforced tourmaline-modified asphalt and the preparation of graphene/tourmaline-composite-modified asphalt.

Therefore, this study aims to enhance the road performance and emission reduction effect of tourmaline-modified asphalt by graphene and obtain more excellent inorganic material modified asphalt. The preparation process parameters of graphene/tourmalinecomposite-modified asphalt were optimized. The basic performances, rheological performance and emission reduction effect of graphene/tourmaline-composite-modified asphalt were studied. The enhancement effect of graphene on the tourmaline-modified asphalt performance was clarified. The scanning electron microscope (SEM) and differential scanning calorimetry (DSC) were used to determine the micromorphology and dispersion of graphene/tourmaline in the composite modified asphalt and the mechanism of graphene/tourmaline synergetic strengthening asphalt performance. It lays a foundation for further research and application of graphene/tourmaline-composite-modified asphalt.

\section{Materials and Experimental}

\subsection{Materials}

The materials mainly include graphene, tourmaline and 70\# base asphalt. Tourmaline belongs to borosilicate minerals and its appearance is black powder. The tourmaline (Figure 1a) contains a lot of $\mathrm{SiO}_{2}, \mathrm{Al}_{2} \mathrm{O}_{3}$ and $\mathrm{Fe}_{2} \mathrm{O}_{3}$, and the content of $\mathrm{Fe}_{2} \mathrm{O}_{3}$ is more than $20 \%$. Its average particle size is $7.21 \mu \mathrm{m}$, and $60 \%$ of the particles are concentrated in the range of 3.4 to $6.6 \mu \mathrm{m}$. The graphene (Figure 1b) used in this study was prepared by physical method. It is mainly composed of few layers (3-8 layers) of graphene black powder. Its purity is more than $90 \mathrm{wt} \%$, the monolayer ratio is more than $30 \%$, the thickness 
is $1.0-1.77 \mathrm{~nm}$ and the average diameter is $11.56 \mathrm{um}$. The graphene/tourmaline composite powder was prepared by ball milling method [16]. Its material cost is USD 0.8-1.0/g. AH-70\# asphalt is used, and its main technical indices are shown in Table 1.
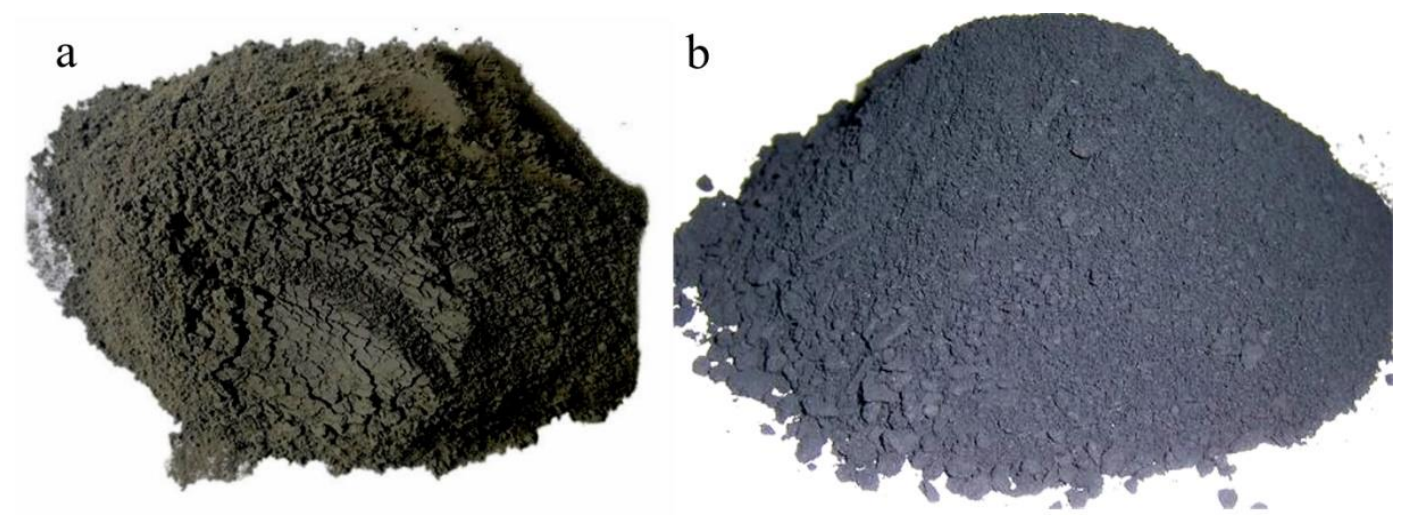

Figure 1. The appearance of tourmaline (a) and few-layer graphene (b).

Table 1. Technical indices of base asphalt.

\begin{tabular}{|c|c|c|c|c|c|c|c|c|}
\hline \multirow{2}{*}{$\begin{array}{l}\text { Technical } \\
\text { Index }\end{array}$} & \multirow{2}{*}{$\begin{array}{l}\text { Penetration } \\
\left(25^{\circ} \mathrm{C}\right) / 0.1 \mathrm{~mm}\end{array}$} & \multirow{2}{*}{$\begin{array}{l}\text { Penetration } \\
\text { Index }\end{array}$} & \multirow{2}{*}{$\begin{array}{l}\text { Softening } \\
\text { Point } /{ }^{\circ} \mathrm{C}\end{array}$} & \multirow{2}{*}{$\begin{array}{l}\text { Ductility } \\
\left(10^{\circ} \mathrm{C}\right) / \mathrm{cm}\end{array}$} & \multirow{2}{*}{$\begin{array}{l}60{ }^{\circ} \mathrm{C} \text { Dynamic } \\
\text { Viscosity/(Pa.s) }\end{array}$} & \multicolumn{3}{|c|}{$\begin{array}{c}\text { Anti-Aging Resistant Performance } \\
\text { (RTFOT) }\end{array}$} \\
\hline & & & & & & $\begin{array}{l}\text { Weight } \\
\text { Change/\% }\end{array}$ & $\begin{array}{c}\text { Residual } \\
\text { Penetration } \\
\text { Ratio/\% }\end{array}$ & $\begin{array}{l}\text { Ductility } \\
\left(10^{\circ} \mathrm{C}\right) / \mathrm{cm}\end{array}$ \\
\hline $\begin{array}{c}\text { Test } \\
\text { value }\end{array}$ & 64 & -1.37 & 47.9 & 38.3 & 226 & 0.12 & 74.1 & 12.4 \\
\hline
\end{tabular}

\subsection{Preparation Method and Scheme of Modified Asphalt}

The preparation process of graphene/tourmaline-composite-modified asphalt is as follows:

1. The graphene/tourmaline composites were prepared by ball milling [16]. Absolute ethanol was used as the ball milling medium and poured into the beaker. The beaker was placed in the ultrasonic dispersion instrument. Then, graphene was slowly added into the beaker and stirred with a glass rod until the graphene was evenly dispersed in absolute ethanol. Tourmaline powder was slowly added into beaker to form graphene-tourmaline-absolute ethanol suspension. Then, the suspension was poured into the container of the ball mill. After rinsing the beaker with some absolute ethanol, the rinsing liquid was poured into the container. Next, the ball mill was started. The conditions were as follows: ball milling speed was $200 \mathrm{rpm}$ and ball milling time was $2 \mathrm{~h}$. After completion, the composite was dried, dispersed and stored for use.

2. A certain mass of dehydrated AH-70\# asphalt was weighed and heated. According to the mass of asphalt and the content of graphene/tourmaline composite powder, the dried graphene/tourmaline composite powder and titanate coupling agent TC-131 (1.0 $\mathrm{wt} \%$ of asphalt) were weighed and mixed evenly. When the asphalt had a certain fluidity, the composite powder material was poured into asphalt and stirred manually for $5 \mathrm{~min}$.

3. After the asphalt was heated to the specified temperature, the high-speed shear disperser was started. First, the asphalt was sheared and dispersed at $1000 \mathrm{rpm}$ for $10 \mathrm{~min}$. Then, the speed was adjusted to the specified shear speed and the asphalt was sheared and dispersed for a specified time. The temperature must be accurately controlled in the process of asphalt modification.

4. The prepared graphene/tourmaline-composite-modified asphalt was manually stirred for $10 \mathrm{~min}$ to remove the bubbles in the modified asphalt, and then stored for use. 
To optimize the preparation process parameters of graphene/tourmaline-compositemodified asphalt, three factors and three levels of an orthogonal test were designed as shown in Table 2. In this experiment, the content of graphene is $1.0 \mathrm{wt} \%$ of tourmaline, and the content of composite powder material is $20 \mathrm{wt} \%$ of asphalt.

Table 2. $\mathrm{L}_{9}\left(3^{3}\right)$ orthogonal experimental design.

\begin{tabular}{cccc}
\hline \multirow{2}{*}{ No. } & \multicolumn{3}{c}{ Factors and Levels } \\
\cline { 2 - 4 } & Shear Temperature $/{ }^{\circ} \mathbf{C}$ & Shear Speed/rmp & Shear Time/min \\
\hline 1 & 170 & 4000 & 20 \\
2 & 130 & 3000 & 60 \\
3 & 170 & 2000 & 60 \\
4 & 130 & 4000 & 40 \\
5 & 150 & 4000 & 60 \\
6 & 170 & 3000 & 40 \\
7 & 150 & 3000 & 20 \\
8 & 150 & 2000 & 40 \\
9 & 130 & 2000 & 20 \\
\hline
\end{tabular}

To study the influence of the graphene content and the composite powder material content on the asphalt performance, the modified asphalt was prepared according to the test scheme as shown in Table 3 under the optimal preparation process parameters. Then, its performance was tested. In this experiment, $G$ represented graphene, and $T$ represented tourmaline. The subscript 1.0/100 represented the mass ratio of graphene to tourmaline.

Table 3. Preparation scheme of graphene/tourmaline-composite-modified asphalt.

\begin{tabular}{ccccc}
\hline No. & Asphalt Type & \multicolumn{3}{c}{ Modifier Content/\% } \\
\hline 1 & Base asphalt & 10 & - & 30 \\
2 & T modification & 10 & 20 & 30 \\
3 & $\mathrm{G}_{0.5} / \mathrm{T}_{100}$ modification & 10 & 20 & 30 \\
4 & $\mathrm{G}_{1.0} / \mathrm{T}_{100}$ modification & 10 & 20 & 30 \\
5 & $\mathrm{G}_{1.5} / \mathrm{T}_{100}$ modification & 10 &
\end{tabular}

Note: The modifier content is expressed as \% by asphalt weight.

\subsection{Basic Performance Test Method}

According to ASTM D5, ASTM D36 and ASTM D113, the penetration $(P)$, softening point and ductility of asphalt were tested, respectively. The penetration index $(P I)$ and equivalent softening point $\left(T_{800}\right)$ were calculated. According to ASTM D2872, the asphalt was aged by the rolling thin film oven test (RTFOT). The penetration and softening point of aged asphalt were measured, and the residual penetration ratio and softening point increment were calculated. According to the specifications, the number of samples used under each test condition was 3.

- Penetration

In order to calculate the $P I$, the penetration at $15^{\circ} \mathrm{C}, 25^{\circ} \mathrm{C}$ and $30^{\circ} \mathrm{C}$ was tested, respectively. Penetration-temperature sensitivity coefficient $(A)$ and regression coefficient $(K)$ were obtained by regression analysis. The relationship between penetration and test temperature was shown in Equation (1). The PI and $T_{800}$ were calculated according to Equations (2) and (3), respectively, as follows:

$$
\begin{gathered}
\lg P=A T+K, \\
P I=30 /(1+50 A)-10, \\
T_{800}=(\lg 800-K) / A,
\end{gathered}
$$


where $P$ is penetration, $0.1 \mathrm{~mm} ; \mathrm{T}$ is test temperature, ${ }^{\circ} \mathrm{C} ; A$ is penetration-temperature sensitivity coefficient; $K$ is regression coefficient; $P I$ is penetration index; $T_{800}$ is equivalent softening point.

- Softening point

The softening point is determined by the softening point meter. The asphalt sample was put into the copper ring with the specified size (inner diameter $18.9 \mathrm{~mm}$ ). Standard steel ball (mass of $3.5 \mathrm{~g}$ ) was placed on the test piece and placed in water or glycerin. The water or glycerin was heated at the specified heating rate $\left(5^{\circ} \mathrm{C} / \mathrm{min}\right)$ to make the asphalt soften. Softening point is the temperature at which the ball drops to a specified distance (25.4 mm), expressed in ${ }^{\circ} \mathrm{C}$.

- Ductility

The ductility of asphalt was measured by a ductility meter. The " $\infty$ " shape standard asphalt sample (the minimum section in the middle is $1 \mathrm{~cm}^{2}$ ) was prepared. The ductility is the length of the sample when it is pulled down to the fracture at the specified speed $(5 \pm 0.25 \mathrm{~cm} / \mathrm{min})$ and temperature $\left(10^{\circ} \mathrm{C}\right)$, expressed in $\mathrm{cm}$.

- $\quad$ DSR test

The DSR test of modified asphalt at different temperatures was carried out. The $\mathrm{H}-$ PTD 200 dynamic shear rheometer produced by Anton Paar was used. The specimens were placed between parallel plates with a diameter of $8 \mathrm{~mm}$. The clearance of parallel plates was determined according to the test requirements. The excess asphalt sample outside the parallel plate was scrapped by scraper. In temperature sweep, the control strain was $1 \%$, the frequency was $10 \mathrm{rad} / \mathrm{s}$, and the temperature range was $30-80^{\circ} \mathrm{C}$.

- $\quad$ RTFOT

In the rolling thin film oven test, $35 \mathrm{~g}$ asphalt was put into an open glass bottle with a height of $140 \mathrm{~mm}$ and a diameter of $64 \mathrm{~mm}$. Then the bottle was inserted into a rotary oven at a high temperature of $163{ }^{\circ} \mathrm{C}$. The hot air was blown in at a flow rate of $4000 \mathrm{~mL} / \mathrm{min}$, and the bottle was rotated at a speed of $15 \mathrm{r} / \mathrm{min}$. The aging treatment time was $75 \mathrm{~min}$. Finally, the penetration and softening point of aged asphalt were measured, and the residual penetration ratio and softening point increment were calculated, respectively.

\subsection{Emission Reduction Effect Test Method}

- Test method of asphalt fume reduction in asphalt heating process

According to GB 31570-2015, the inhibition effect of graphene/tourmaline composites on asphalt fume emission during its heating process is determined. An asphalt fume collection device is used to collect the asphalt fumes generated during the heating process of base asphalt and modified asphalt. The asphalt fume collection device is shown in Figure 2a. The weight difference between the sealed collection bottle containing the collection liquid before and after collection is the weight of the asphalt fumes. In the process of collecting asphalt fumes, the high-speed shear apparatus was used to mix the asphalt, the mixing rate was $3000 \mathrm{rpm}$, the heating temperature was $120-200^{\circ} \mathrm{C}$ and the collection time was $2 \mathrm{~h}$. 


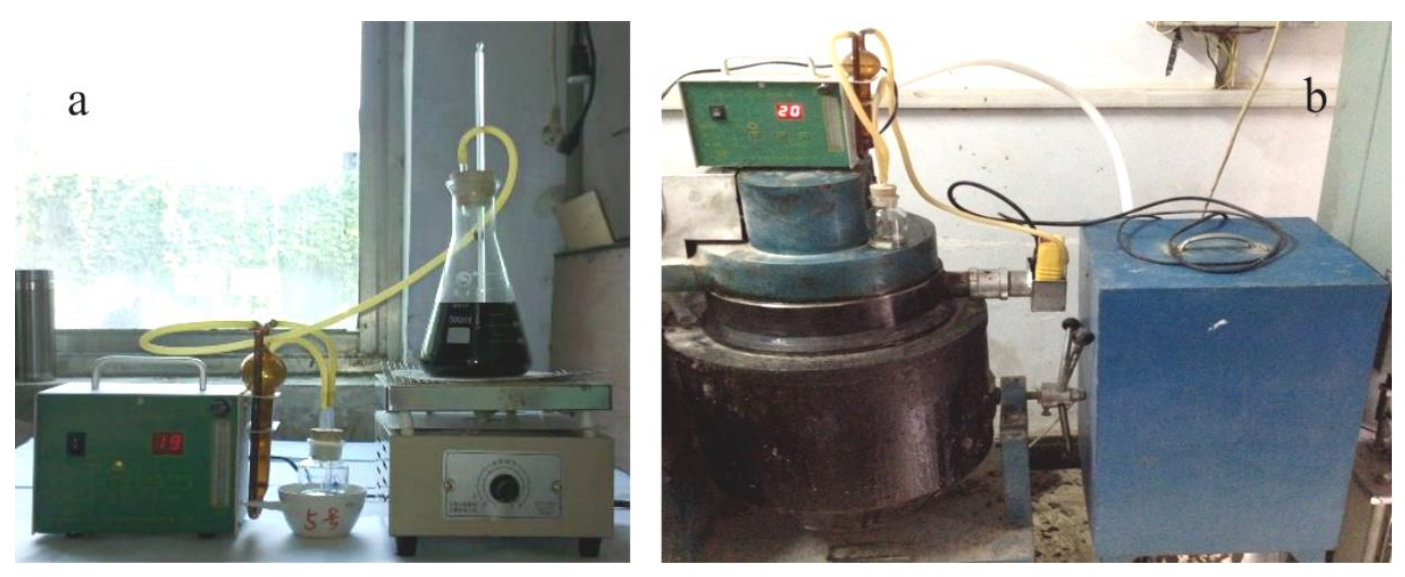

Figure 2. Emission reduction effect test devices: (a) Asphalt fume collection device; (b) Emission reduction test device for asphalt mixture mixing process.

- $\quad$ Test method of emission reduction in asphalt heating process

To determine the inhibition effect of graphene/tourmaline composite material on the emission of gas pollutants in the mixing process of the asphalt mixture, the emission of pollutants such as $\mathrm{CO}_{X}$ and $\mathrm{NO}_{X}$ in the mixing process of asphalt mixture is mainly tested by a self-developed pollutant emission test device for the asphalt mixture [32]. The emission reduction test device for asphalt mixture is shown in Figure $2 b$. The device has the advantages of good airtightness, little environmental impact, high collection efficiency, high detection accuracy and many detection factors. It can efficiently collect and analyze the pollutants produced in the mixing process of asphalt mixture. The specific test steps are as follows:

1. The required aggregates and asphalt were prepared according to the preparation method of asphalt mixture specimen.

2. The heated aggregates were poured into the asphalt mixer, and then the required weight of asphalt was poured in. Next, the pollutant emission test device was connected, and the mixer was started. At the same time, the air inlet valve of the test device was opened to collect the pollutants emitted from the asphalt mixture mixing process. After $90 \mathrm{~s}$ of mixing, the mixer and the air inlet valve were closed.

3. The weighed mineral powder (including graphene/tourmaline composite) was added into the asphalt mixer, and then the mixer was started again. The air inlet valve of the device was opened to collect pollutants again. After $90 \mathrm{~s}$ of mixing, different gas detectors were used to detect the pollutant concentrations at the gas detection port of the device. The average of three valid test results was reported.

\subsection{Microscopic Characterization Method}

- $\quad$ Scanning electron microscopy (SEM)

Scanning electron microscopy (SEM FEI Verios 460 high-resolution field emission scanning electron microscopy) was used to observe micromorphology of the modified asphalt. The dispersion of graphene/tourmaline composite powder in asphalt was studied. To study the influence of the content of graphene/tourmaline composites on its dispersion, the composite modified asphalt with $10 \mathrm{wt} \%$ and $30 \mathrm{wt} \%$ graphene/tourmaline were observed, respectively. The content of graphene in graphene/tourmaline composites is $1.5 \mathrm{wt} \%$.

- Differential scanning calorimeter (DSC)

Differential scanning calorimeter (The DSC 200 F3 made by Netzsch company of Germany) was used to study the influence of graphene/tourmaline composite on the performance of asphalt. The test temperature range was $-40-160{ }^{\circ} \mathrm{C}$, and the heating 
rate was $10{ }^{\circ} \mathrm{C} / \mathrm{min}$. By comparing the DSC images of the modified asphalt and the base asphalt, the influence of the graphene on the performance of tourmaline-modified asphalt was determined. In this test, the modified asphalt with $20 \mathrm{wt} \%$ powder material was selected for research.

\section{Results and Discussion}

\subsection{Optimization of Modified Asphalt Preparation Process Parameters}

According to the orthogonal test scheme, graphene/tourmaline-composite-modified asphalt was prepared by using different process parameters. The penetration, softening point and $10^{\circ} \mathrm{C}$ ductility of the asphalts were tested. The variance analysis and range analysis results of the orthogonal test are shown in Tables 4 and 5, respectively. The change trend of the asphalt's performance index mean value with factor levels are shown in Figure 3.

According to Table 4, the influence of the shear time on the penetration of the modified asphalt is more significant, while that of the shear temperature and speed can be considered as insignificant. For the softening point, the effect of the shear temperature is not significant, but the effect of the shear speed and time is significant. In terms of ductility, the three factors are more significant.

Table 4. Orthogonal test variance analysis for modified asphalt preparation process optimization.

\begin{tabular}{ccccccc}
\hline Index & Factor & $\mathbf{S}_{\mathbf{i}}{ }^{2}$ & $\mathbf{f}_{\mathbf{i}}$ & $\mathbf{S}_{\mathbf{i}}{ }^{2} / \mathbf{f}_{\mathbf{i}}$ & $\mathbf{F}_{\boldsymbol{i}}$ & Sig. \\
\hline \multirow{5}{*}{ Penetration } & Temperature & 0.304 & 2 & 0.152 & 0.123 & 0.890 \\
& speed & 0.322 & 2 & 0.161 & 0.130 & 0.885 \\
& Time & 27.094 & 2 & 13.547 & 10.950 & 0.084 \\
& Error & 2.474 & 2 & 1.237 & $/$ & $/$ \\
& Sum & 30.195 & 8 & $\mathrm{~F}_{0.05}(2,2)=19 ; \mathrm{F}_{0.1}(2,2)=9$ \\
& Temperature & 0.254 & 2 & 0.127 & 1.309 & 0.433 \\
& speed & 3.871 & 2 & 1.935 & 19.963 & 0.048 \\
Softening point & Time & 10.524 & 2 & 5.262 & 54.278 & 0.018 \\
& Error & 0.194 & 2 & 0.097 & $/$ & $/$ \\
& Sum & 14.842 & 8 & $\mathrm{~F}$ & $/$ \\
& Temperature & 78.691 & 2 & 39.346 & 127.480 & 0.008 \\
& speed & 83.877 & 2 & 41.938 & 135.880 & 0.001 \\
& Time & 446.988 & 2 & 223.494 & 724.120 & 0.007 \\
& Error & 0.617 & 2 & 0.309 & $/$ & $/$ \\
& Sum & 610.173 & 8 & \multicolumn{2}{c}{$\mathrm{F}_{0.05}(2,2)=19 ; \mathrm{F}_{0.1}(2,2)=9$} \\
\hline
\end{tabular}

Table 5. Orthogonal test range analysis for modified asphalt preparation process optimization.

\begin{tabular}{|c|c|c|c|c|c|c|c|c|c|c|c|c|}
\hline \multirow{2}{*}{ Factor } & \multicolumn{4}{|c|}{$25^{\circ} \mathrm{C}$ Penetration/(0.1 mm) } & \multicolumn{4}{|c|}{ Softening Point $/{ }^{\circ} \mathrm{C}$} & \multicolumn{4}{|c|}{$10^{\circ} \mathrm{C}$ Ductility/mm } \\
\hline & $\mathbf{k}_{\mathbf{1}}$ & $\mathbf{k}_{2}$ & $\mathbf{k}_{3}$ & Range & $\mathbf{k}_{1}$ & $\mathbf{k}_{2}$ & $\mathbf{k}_{3}$ & Range & $\mathbf{k}_{1}$ & $\mathbf{k}_{2}$ & $\mathbf{k}_{3}$ & Range \\
\hline Temperature & 55.67 & 55.71 & 55.30 & 0.41 & 49.83 & 50.23 & 49.95 & 0.40 & 80.56 & 78.67 & 73.57 & 6.99 \\
\hline Speed & 55.35 & 55.51 & 55.81 & 0.46 & 49.70 & 50.92 & 49.40 & 1.52 & 73.33 & 80.33 & 79.11 & 7.00 \\
\hline Time & 53.39 & 55.66 & 57.63 & 4.24 & 49.18 & 49.30 & 51.53 & 2.35 & 84.00 & 81.00 & 67.78 & 16.22 \\
\hline
\end{tabular}

Note: $\mathrm{k}$ is the comprehensive average of the data at certain level. 

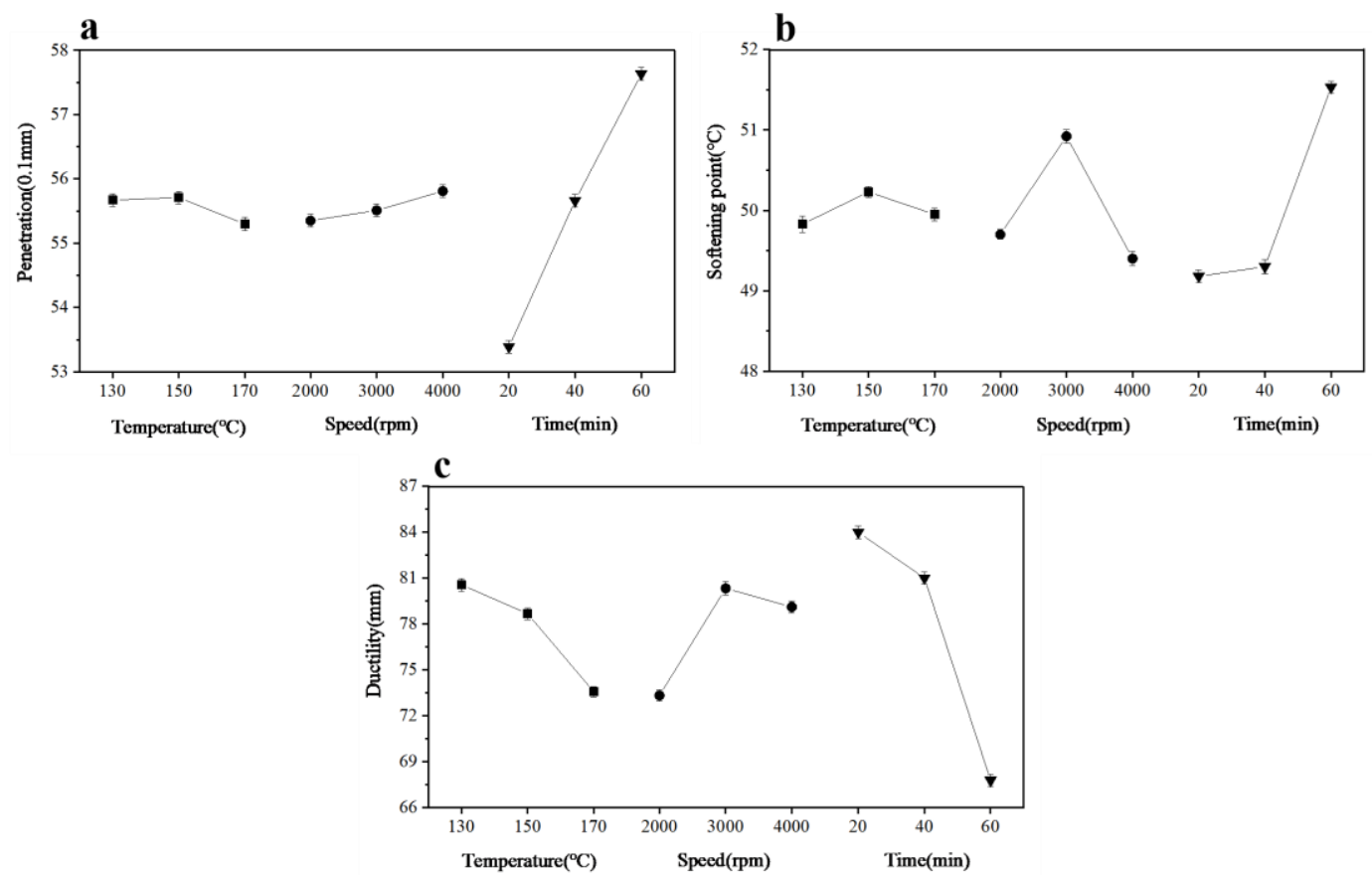

Figure 3. The change trend of asphalt performance index mean value with factor level: (a) Penetration; (b) Softening point; and (c) Ductility.

It can be seen from Table 5 and Figure 3 that the order of influence degree on the penetration, softening point and ductility of the modified asphalt is: shear time $>$ shear speed > shear temperature. Therefore, more attention should be paid to the effect of the shear time when determining the optimal preparation process parameters. The penetration and ductility of the modified asphalt decrease with the increase of the shear time, while the softening point increases with the increase of the shearing time. The main reason for this is that the asphalt was aged due to a long shear time, and the aged asphalt became hard and brittle. So, the appropriate shear time of modified asphalt is $40 \mathrm{~min}$. The penetration of the modified asphalt increases with the increase of the shear speed, while the softening point and ductility increase at first and then decrease. The reason may be that in a certain range of shear speed, the dispersion of the modifier in the asphalt can be improved, and its performance can be enhanced. It is further determined that the optimal shear speed is $3000 \mathrm{rpm}$. The penetration and ductility of the modified asphalt decrease with the increase of the shear temperature, while the softening point first increases and then decreases. The reason for this may be that the high temperature aggravates the aging of the asphalt. However, in a certain temperature range, increasing the temperature is conducive to the dispersion uniformity of the modifier in the asphalt, so as to improve the performance of asphalt. Therefore, the optimal preparation temperature should be $150^{\circ} \mathrm{C}$.

Based on this, the optimal preparation parameters of graphene/tourmaline-compositemodified asphalt are as follows: shear temperature $150{ }^{\circ} \mathrm{C}$, shear speed $3000 \mathrm{rpm}$ and shear time $40 \mathrm{~min}$.

\subsection{Micromorphology and Modifier Dispersion of Modified Asphalt}

An SEM test was used to determine the micromorphology and dispersion of graphene/tourmaline in the composite-modified asphalt. The SEM images of raw materials are shown in Figure 4, and the SEM images of the graphene/tourmaline-compositemodified asphalt are shown in Figures 5 and 6. 

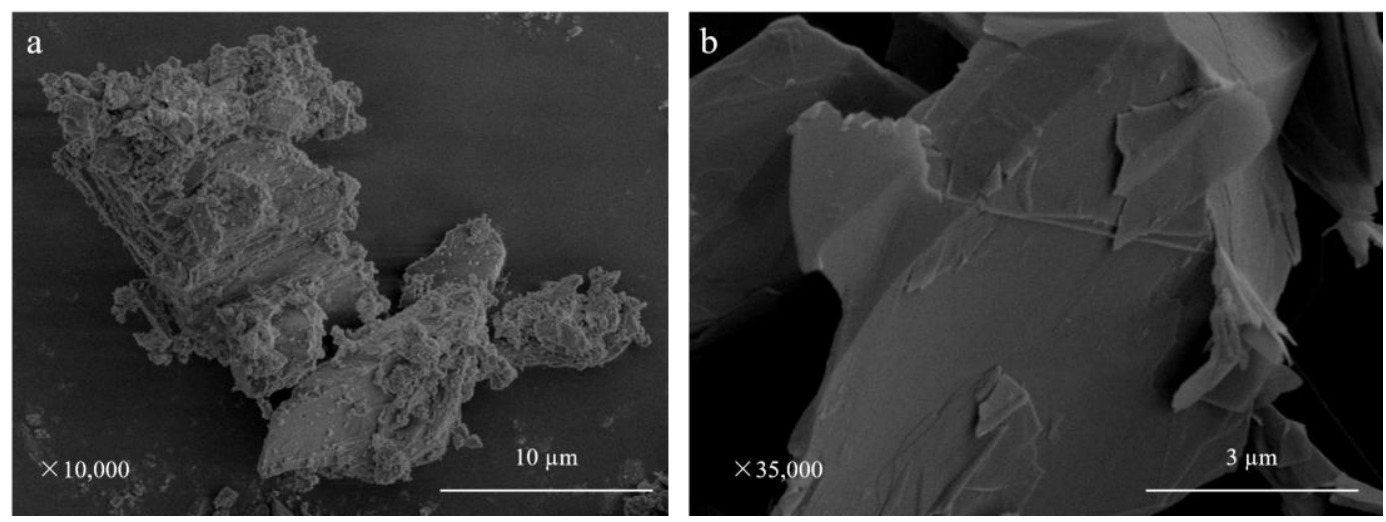

Figure 4. SEM images: (a) Tourmaline $(\times 10,000)$; (b) Graphene $(\times 35,000)$.
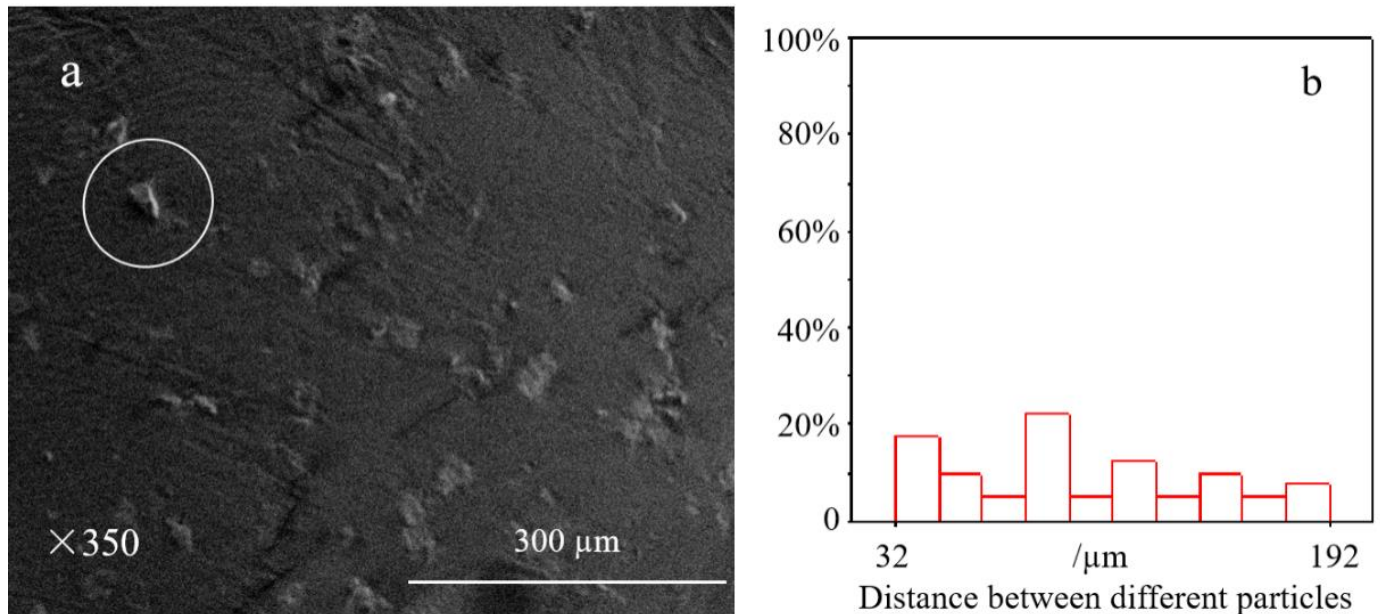

Figure 5. (a) SEM image and (b) particle size distribution of modified asphalt with $10 \mathrm{wt} \% \mathrm{G}_{1.5} / \mathrm{T}_{100}$.
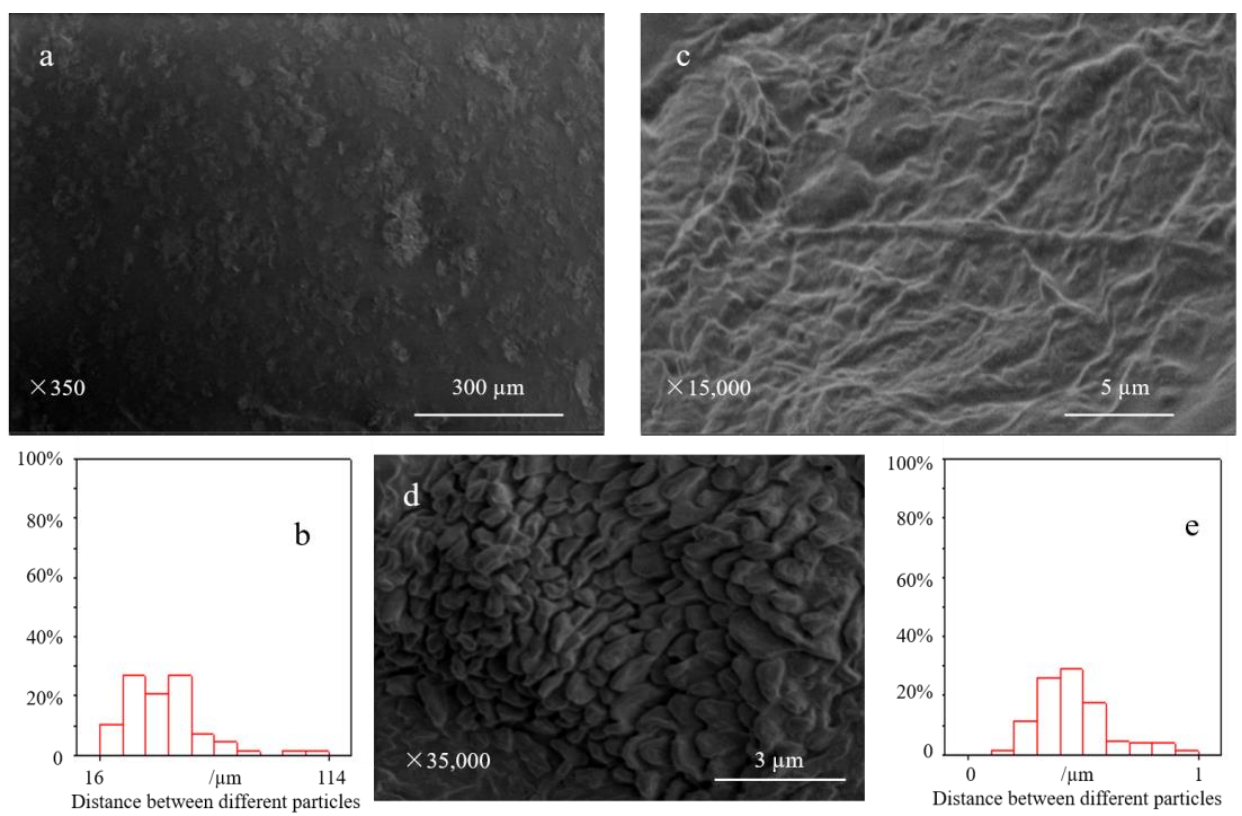

Figure 6. SEM images and particle size distributions of modified asphalt with $30 \mathrm{wt} \% \mathrm{G}_{1.5} / \mathrm{T}_{100}$ : (a) SEM (×350); (b) Particle size distribution $(\times 350)$; (c) SEM $(\times 15,000)$; (d) SEM $(\times 35,000)$; (e) Particle size distribution $(\times 35,000)$. 
From Figure 4, the SEM image of tourmaline with a magnification of 10,000 times shows that tourmaline is granular, rod-like and lump, and tourmaline shows an obvious multi-layer structure. The SEM image of graphene shows that it is characterized by extremely thin lamellar folds and multi-layer overlapping. The surface of graphene shows a certain degree of micro roughness, but the surface is dense without pore structure.

It can be seen from Figures 5 and $6 a$ that the graphene/tourmaline composites are presented in the SEM images in the form of flakes and particles. Its distribution is uniform without obvious agglomeration. In the SEM images of graphene/tourmaline-modified asphalt with $10 \mathrm{wt} \% \mathrm{G}_{1.5} / \mathrm{T}_{100}$, the maximum distance between adjacent modifier particles is $191.93 \mu \mathrm{m}$, the minimum distance is $32.64 \mu \mathrm{m}$ and the average distance is $101.14 \mu \mathrm{m}$. In the SEM images of the graphene/tourmaline-modified asphalt with $30 \mathrm{wt} \% \mathrm{G}_{1.5} / \mathrm{T}_{100}$, the maximum distance between the adjacent modifier particles is $113.7 \mu \mathrm{m}$, the minimum distance is $16.02 \mu \mathrm{m}$ and the average distance is $43.71 \mu \mathrm{m}$. With the increase of the modifier content, the distance between the particles decreases and the particle distribution becomes more compact. It is beneficial for composite materials to play their functional properties in asphalt.

To clearly observe the micromorphology and dispersion of the composite materials in asphalt, a random point was selected from the 350 times enlarged SEM image of modified asphalt, and the magnification was up to 15,000 times. The SEM image of the graphene/tourmaline-composite-modified asphalt shows a crisscross network structure, which may be caused by the disorderly distribution of the rod-shaped structure of tourmaline. Both graphene and tourmaline have a layered structure. There are many folds on the surface of graphene, and there are obvious gaps between the layered structures of tourmaline, which makes it have a large specific surface area. It means that the bonding area between the asphalt and the graphene/tourmaline composite is larger, and the molecular force between them is larger. At the same time, due to the adsorption and capillary action, the asphalt seeps into the gaps of tourmaline, which increases the contact bonding area. This is beneficial for improving the adhesion between the asphalt and the graphene/tourmaline composites. As the main component of the composite is inorganic mineral powder, it cannot be dissolved in asphalt and can only be filled in with asphalt. According to Figure $6 \mathrm{c}$, there is no obvious angular structure on the surface of the graphene/tourmaline composite after being coated with asphalt. The mineral particle modifier can be completely wrapped in asphalt without obvious interface, which indicates that the composite has good compatibility with asphalt. Furthermore, randomly select a point in Figure 6c and enlarge it to 35,000 times for observation. From Figure 6d, the SEM image shows that the graphene/tourmaline particles are closely adsorbed on the asphalt membrane in clusters, and the particles are arranged closely. The maximum particle size, minimum particle size and average particle size of the graphene/tourmaline composite coated with asphalt film are $0.99 \mu \mathrm{m}, 0.16 \mu \mathrm{m}$ and $0.45 \mu \mathrm{m}$, respectively. Moreover, $84.5 \%$ of the particles are concentrated in 0.2 to $0.6 \mu \mathrm{m}$. This shows that in the process of modified asphalt preparation, the graphene/tourmaline composite powder is ground by the high-speed shear disperser, and its particle size is reduced to a certain extent.

\subsection{Basic Performance}

Different graphene/tourmaline-composite-modified asphalts were prepared according to the optimum preparation parameters. The temperature susceptibility, high temperature and anti-aging properties of graphene/tourmaline-composite-modified asphalt have been studied. The enhancement effect of graphene on the performance of tourmalinemodified asphalt was confirmed.

\subsubsection{Temperature Susceptibility Performance}

The penetration of each modified asphalt was tested at $15^{\circ} \mathrm{C}, 25^{\circ} \mathrm{C}$ and $30^{\circ} \mathrm{C}$. The penetration index was calculated. The influence of the content of the graphene/tourmaline 
composite powder on the temperature susceptibility performance of asphalt was analyzed. The results are shown in Figure 7.

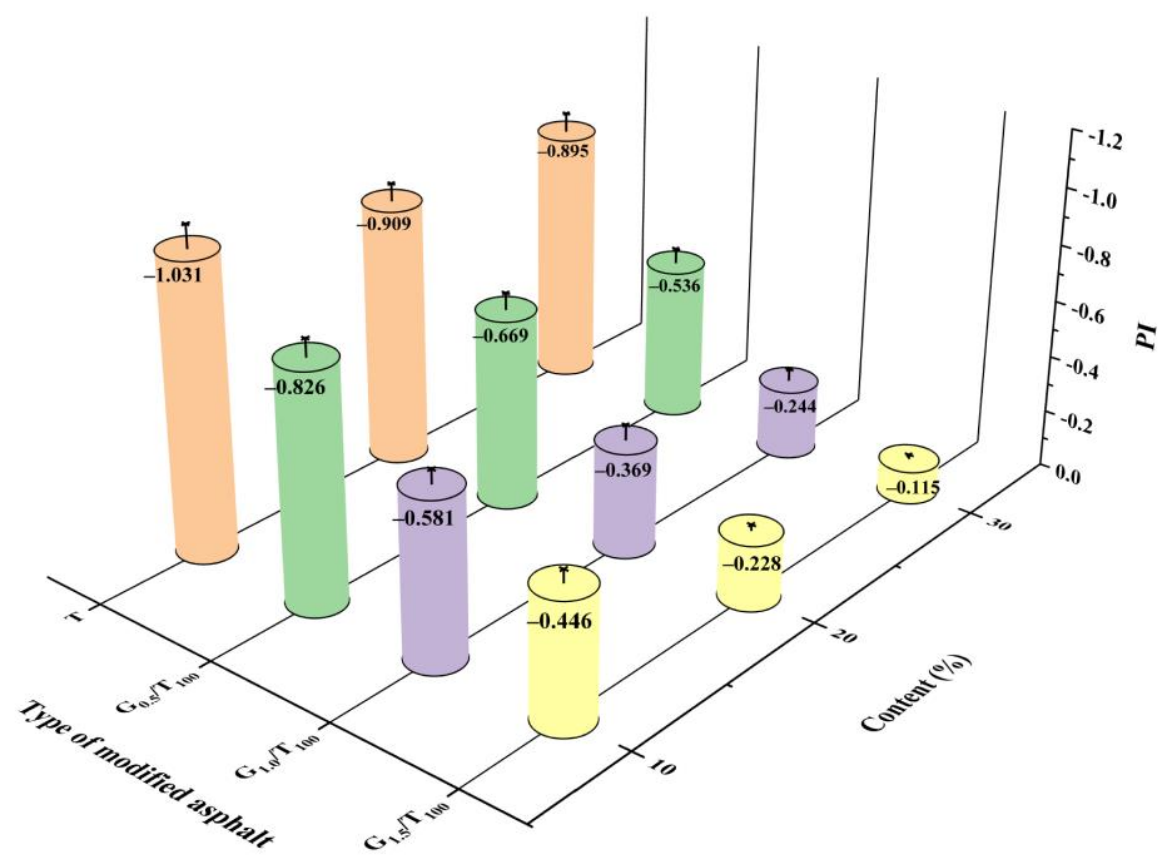

Figure 7. Penetration index of graphene/tourmaline-composite-modified asphalt.

It can be seen from Table 1 and Figure 7 that the penetration indices of the graphene/tourmaline-composite-modified asphalt and tourmaline-modified asphalt are higher than that of base asphalt. The penetration index of the graphene/tourmalinecomposite-modified asphalt is higher than that of the tourmaline-modified asphalt. This indicates that the modified asphalt has a lower temperature susceptibility, and the addition of graphene is beneficial to improve the temperature susceptibility performance of asphalt.

Compared with the base asphalt, when the powder content is increased from $10 \%$ to $30 \%$, the penetration index value of tourmaline-modified asphalt increases from -1.031 to -0.895 , an increase of $21.7-32.0 \%$; the penetration index value of the graphene/tourmalinecomposite-modified asphalt increases from -0.826 to -0.115 , an increase of $37.3 \%$ to $91.3 \%$. It shows that the improvement range of the penetration index of the graphene/tourmalinecomposite-modified asphalt is greater than that of the tourmaline-modified asphalt.

Compared with tourmaline-modified asphalt, the higher the content of graphene in the composite powder material, the greater the increase of the penetration index of the graphene/tourmaline-composite-modified asphalt. The temperature susceptibility of asphalt is also weaker, and the graphene/tourmaline composite has better effects on improving the temperature susceptibility of asphalt. The penetration index of graphene/tourmaline-composite-modified asphalt increases with the increase of the content of composite powder. When the content of composite powder is $30 \%$ and the content of graphene is increased from $0.5 \%$ to $1.5 \%$, the penetration index of graphene/tourmalinecomposite-modified asphalt increases from -0.536 to -0.115 , increasing by $40.1-87.2 \%$. The reason may be that the specific surface area of graphene/tourmaline composite is larger than that of tourmaline, which makes more asphalt contact with the composite powder, thus reducing the temperature sensitivity of asphalt.

\subsubsection{High Temperature Performance}

To study the influence of the content of graphene/tourmaline composite powder on the high temperature performance of asphalt, the penetration and softening point of each asphalt were tested, and the equivalent softening point was calculated. The results are shown in Figure 8. 


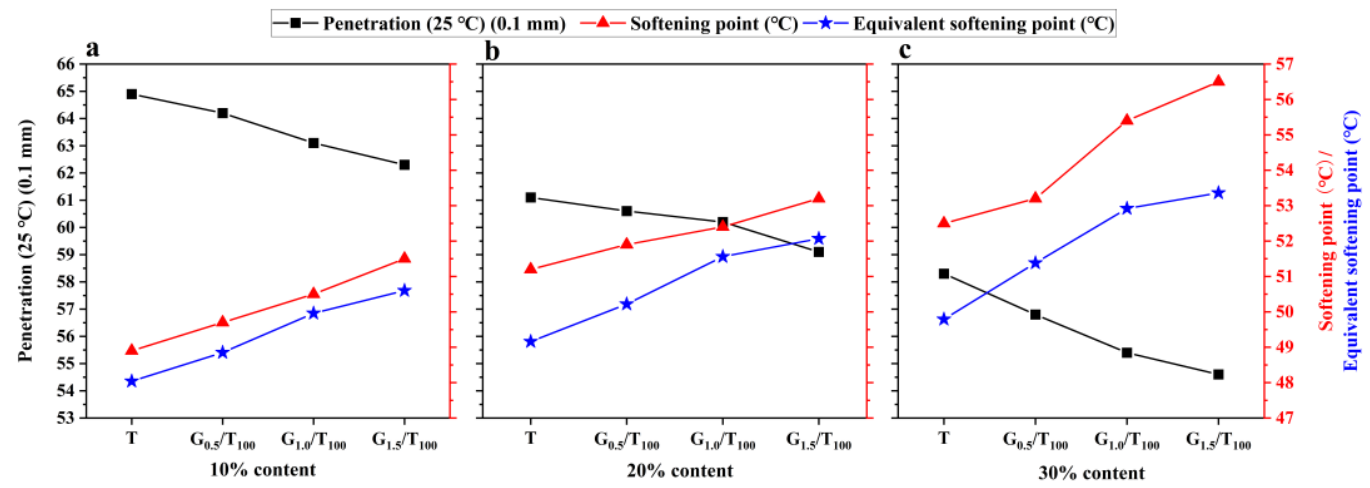

Figure 8. Penetration, softening point and equivalent softening point of graphene/tourmaline-composite-modified asphalt: (a) With $10 \mathrm{wt} \%$ powder content; (b) With $20 \mathrm{wt} \%$ powder content; (c) With $30 \mathrm{wt} \%$ powder content.

From Table 1 and Figure 8, compared with base asphalt, after the modification with tourmaline or the graphene/tourmaline composite, the high temperature performance of asphalt can be significantly improved. The specific change trend is that the $25^{\circ} \mathrm{C}$ penetration decreases gradually with the increase of modifier content, and the softening point and the equivalent softening point increase gradually. At the same content of powder material, the high temperature performance of the graphene/tourmaline-composite-modified asphalt is better than that of the tourmaline-modified asphalt.

Compared with the tourmaline-modified asphalt, with the increase of graphene content, the penetration of the graphene/tourmaline-composite-modified asphalt decreases more significantly, and the softening point and equivalent softening point increase more significantly. When the content of the composite powder material is $30 \%$ and the content of graphene is increased from $0.5 \%$ to $1.5 \%$, the $25^{\circ} \mathrm{C}$ penetration of the graphene/tourmalinecomposite-modified asphalt decreases by $0.15-0.37 \mathrm{~mm}$, the softening point increases by $0.70-4.00{ }^{\circ} \mathrm{C}$ and the equivalent softening point increases by 1.59 to $3.57^{\circ} \mathrm{C}$. Within the research content range, the results show that the high temperature performance of tourmaline-modified asphalt is obviously improved with the increase of graphene content.

Analysis of the reasons for this may be that the polarization effect of the composite material is greater than that of tourmaline [16]. On the other hand, the unique twodimensional lamellar structure of graphene and its surface fold structure play a certain protective and curing effect on the asphalt. It is beneficial to increase the viscosity of asphalt at higher temperatures and improve its high temperature performance to a certain extent.

\subsubsection{Rheological Performance}

As a typical viscoelastic material, the performance of asphalt is strongly dependent on temperature. In the process of pavement use, asphalt needs to bear a certain temperature load coupling effect. Through the temperature scanning test, the rheological performance of graphene/tourmaline-composite-modified asphalts are tested, and the results are shown in Figures 9 and 10. 


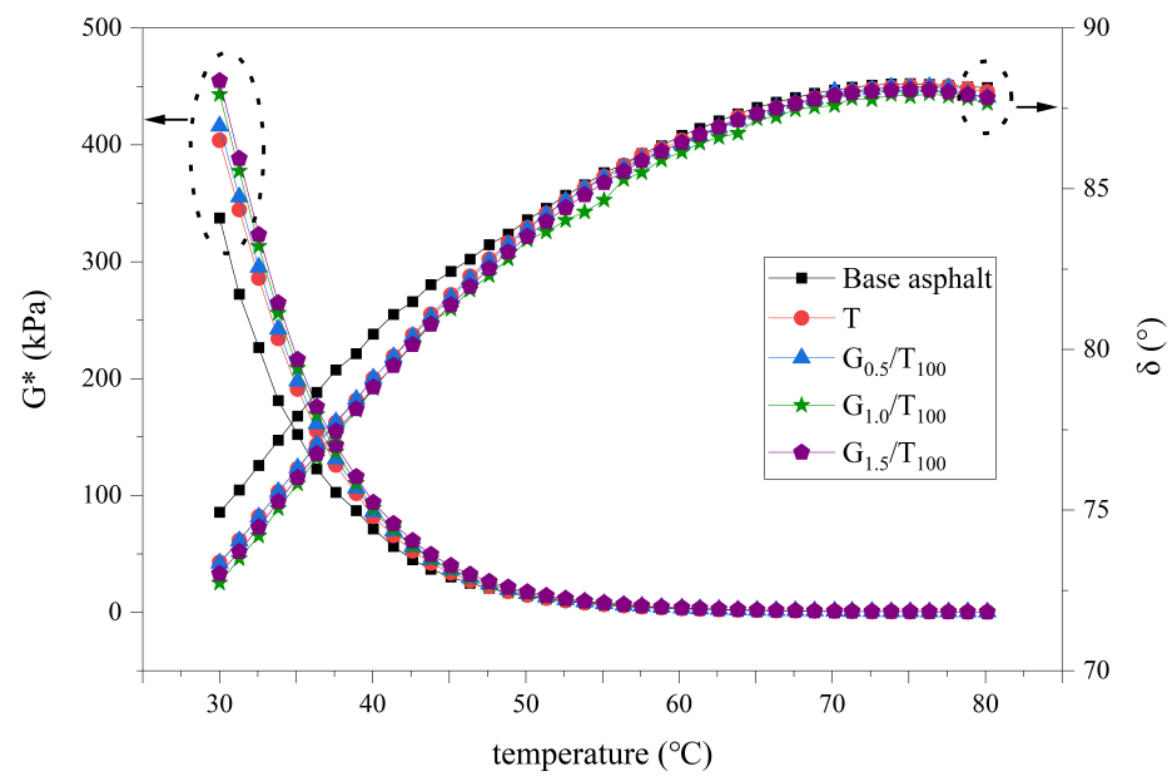

Figure 9. Complex shear modulus $\left(\mathrm{G}^{*}\right)$ and phase angle $(\delta)$ of different graphene/tourmalinecomposite-modified asphalts.

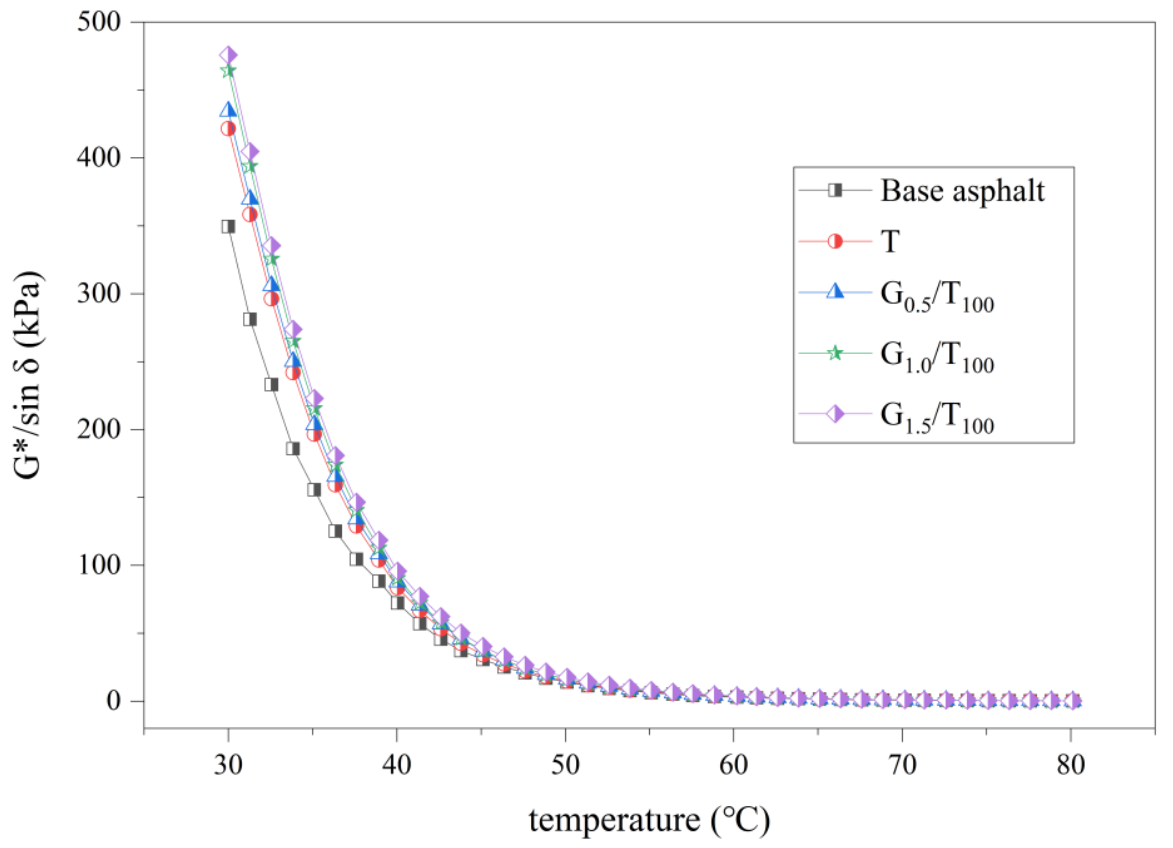

Figure 10. Rutting factor $\left(\mathrm{G}^{*} / \sin \delta\right)$ of different graphene/tourmaline-composite-modified asphalts.

From Figure 9, the rheological performance of the graphene/tourmaline-compositemodified asphalt, tourmaline-modified asphalt and base asphalt basically have the same change trend with temperature. The complex shear modulus decreases exponentially with the increase of temperature, indicating that graphene/tourmaline composites do not change the viscoelastic performance of asphalt. However, at the same temperature, the complex shear modulus of different types of graphene/tourmaline-composite-modified asphalts is higher than that of tourmaline-modified asphalt and base asphalt. In the test temperature range of $30-50{ }^{\circ} \mathrm{C}$, the difference of complex shear modulus between modified asphalt and base asphalt is obvious. In general, the complex shear modulus of composite modified asphalt is higher than that of tourmaline-modified asphalt. The complex shear modulus of $\mathrm{G}_{1.5} / \mathrm{T}_{100}$ composite modified asphalt is the highest. When the test temperature 
exceeds $50{ }^{\circ} \mathrm{C}$, the complex shear modulus of different asphalts is at a low level, and there is little difference between modified asphalt and base asphalt.

The phase angle increases with the increase of temperature. When the test temperature rises from $30^{\circ} \mathrm{C}$ to $80^{\circ} \mathrm{C}$, the phase angles of different types of asphalt are within $88^{\circ}$, indicating that the viscoelastic performance of asphalt are not changed after adding graphene/tourmaline composites material. In the test temperature range of $30-50{ }^{\circ} \mathrm{C}$, the phase angle of different asphalts increases rapidly with the temperature. The phase angle of each modified asphalt is lower than that of the base asphalt, and the phase angle difference between different types of graphene/tourmaline-composite-modified asphalts is small. When the test temperature exceeds $55^{\circ} \mathrm{C}$, the phase angle of different asphalts increases slowly with the increase of temperature. The phase angle of graphene/tourmalinecomposite-modified asphalt is less different from that of tourmaline-modified asphalt and base asphalt, and the phase angle of $\mathrm{G}_{1.0} / \mathrm{T}_{100}$-composite-modified asphalt is the smallest.

It can be seen from Figure 10 that the change trend of rutting factor with temperature of different graphene/tourmaline-composite-modified asphalt is basically consistent with that of tourmaline-modified asphalt and base asphalt. The rutting factor decreases exponentially with the increase of temperature, but the rutting factor of graphene/tourmaline-compositemodified asphalt is greater than that of tourmaline-modified asphalt and base asphalt, indicating that graphene/tourmaline composite is better than tourmaline in improving the rutting resistance of asphalt. In the test temperature range of $30-50{ }^{\circ} \mathrm{C}$, the difference of rutting factor between modified asphalt and base asphalt is obvious, but the difference of rutting factor between different types of graphene/tourmaline-composite-modified asphalt is relatively small. When the temperature exceeds $50{ }^{\circ} \mathrm{C}$, the rutting factor of different asphalts are at a low level, and there is little difference between modified asphalt and base asphalt.

Different types of graphene/tourmaline composite materials show different changes in the improvement range of asphalt rutting factor. When the temperature is lower than $50{ }^{\circ} \mathrm{C}$, the improvement range of rutting factor increases gradually with the increase of graphene content. When the temperature is higher than $50{ }^{\circ} \mathrm{C}$, the improvement range of rutting factor first decreases and then increases with the increase of graphene content. The rutting resistance of $\mathrm{G}_{1.5} / \mathrm{T}_{100}$-composite-modified asphalt is the best. Compared with base asphalt, the rutting factor is improved by $19 \%$ to $20 \%$.

\subsubsection{Anti-Aging Performance}

The asphalt was aged by RTFOT. The penetration and softening point of the asphalt after aging were measured. The residual penetration ratio and softening point increment were calculated respectively. The effects content of graphene/tourmaline composite powder on the asphalt anti-aging performance were studied. The results are shown in Figure 11.

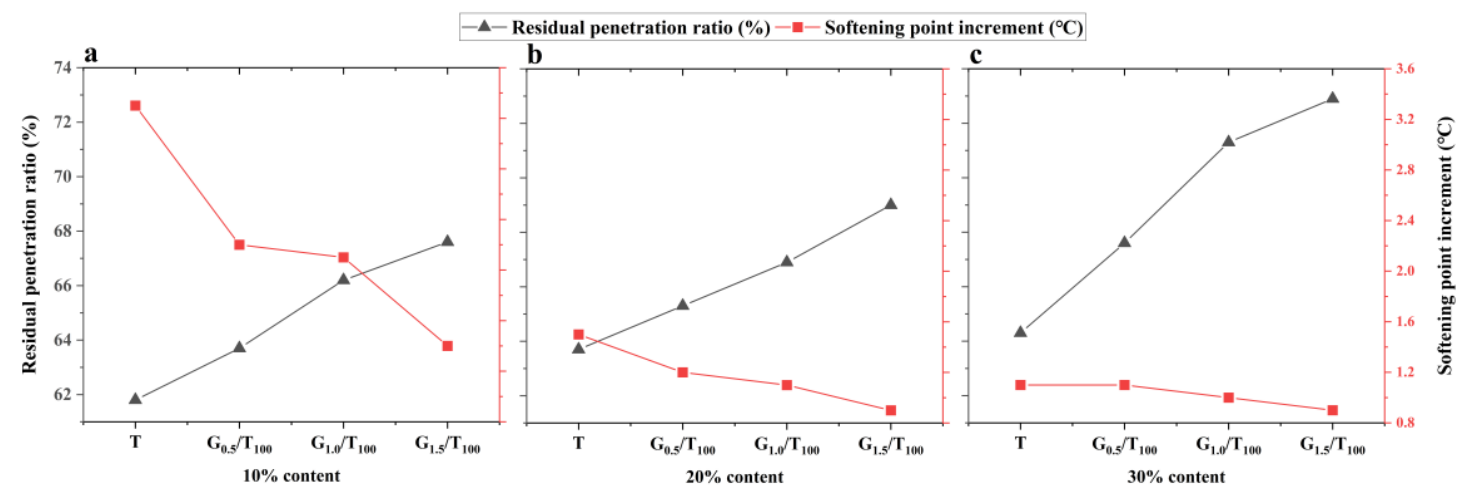

Figure 11. Residual penetration ratio and softening point increment of graphene/tourmaline-composite-modified asphalt after RTFOT: (a) With $10 \mathrm{wt} \%$ powder content; (b) With $20 \mathrm{wt} \%$ powder content; and (c) With $30 \mathrm{wt} \%$ powder content. 
It can be seen from Figure 11 that compared with the base asphalt, the residual penetration ratio of tourmaline-modified asphalt and graphene/tourmaline-compositemodified asphalt increases with the increase of the powder material content. The softening point increment decreases with the increase of its content. It shows that the anti-aging performance of asphalt increases with the increase of the powder material content, and the addition of a powder modifier can slow down the aging degree of asphalt. $G_{1.5} / T_{100}$ has the most significant effect on improving the anti-aging performance of asphalt. When the composite powder content is $30 \mathrm{wt} \%$, the residual penetration ratio is $72.9 \%$, the performance is increased by $15.7 \%$, the softening point increment is only $0.9{ }^{\circ} \mathrm{C}$ and the performance is increased by $88.75 \%$.

Compared with the tourmaline-modified asphalt, the residual penetration ratio and softening point increment of the graphene/tourmaline-composite-modified asphalt are improved in varying degrees after adding graphene. When the powder content is $10 \mathrm{wt} \%$, the residual penetration ratio and softening point increment of $\mathrm{G}_{0.5} / \mathrm{T}_{100}$-composite-modified asphalt increases by $1.9 \%$ and $33.33 \%$, respectively. With the increase of graphene content to $1.0-1.5 \%$, their improvement range is more significant, reaching $4.4-5.8 \%$ and $36.36-57.58 \%$, respectively. The same change trend appears under the $20 \mathrm{wt} \%$ and $30 \mathrm{wt} \%$ powder contents. Analysis of the reasons for this may be that the far-infrared emissivity of tourmaline is improved to a certain extent after graphene is compounded with tourmaline [17], and its energy consumption rate is higher than that of tourmaline. These properties of graphene/tourmaline composites are better than that of tourmaline in delaying the conversion rate of oil to asphaltene during aging. Therefore, the anti-aging performance of graphene/tourmaline-composite-modified asphalt is better than that of tourmaline-modified asphalt.

\subsection{The Emission Reduction Effect of Hot Mixing}

The emission of pollutants in the process of asphalt heating and asphalt mixture mixing were tested. The emission reduction effect of different graphene/tourmalinecomposite-modified asphalts and their mixtures were evaluated.

\subsubsection{Analysis of Asphalt Fume Emission Reduction Effect}

Graphene/tourmaline-composite-modified asphalts were prepared. The emission reduction effect of graphene/tourmaline-composite-modified asphalt during its heating was tested according to the test method described in Section 2.4. The asphalt fume emission and emission reduction rate at different temperatures are shown in Figure 12.

In Figure 12, under the same temperature, the asphalt fume emission of the graphene/tourmaline-composite-modified asphalt is significantly lower than that of the tourmaline-modified asphalt and the base asphalt, and the inhibition effect on the asphalt fume emission becomes more significant with the increase of its content. As the heating temperature of the asphalt increases, the emission of asphalt fumes increases, but as the powder material content increases, the increase in the emission of asphalt fumes with the increase of temperature becomes smaller. It shows that tourmaline and graphene/tourmaline composites can reduce the temperature sensitivity of asphalt fumes. Compared to base asphalt, the highest emission reduction rate in asphalt fumes by adding tourmaline can reach $77.96 \%$, and the highest emission reduction rates in $\mathrm{G}_{0.5} / \mathrm{T}_{100}, \mathrm{G}_{1.0} / \mathrm{T}_{100}$ and $\mathrm{G}_{1.5} / \mathrm{T}_{100}$ can reach $79.56 \%, 81.46 \%$ and $82.77 \%$, respectively. 

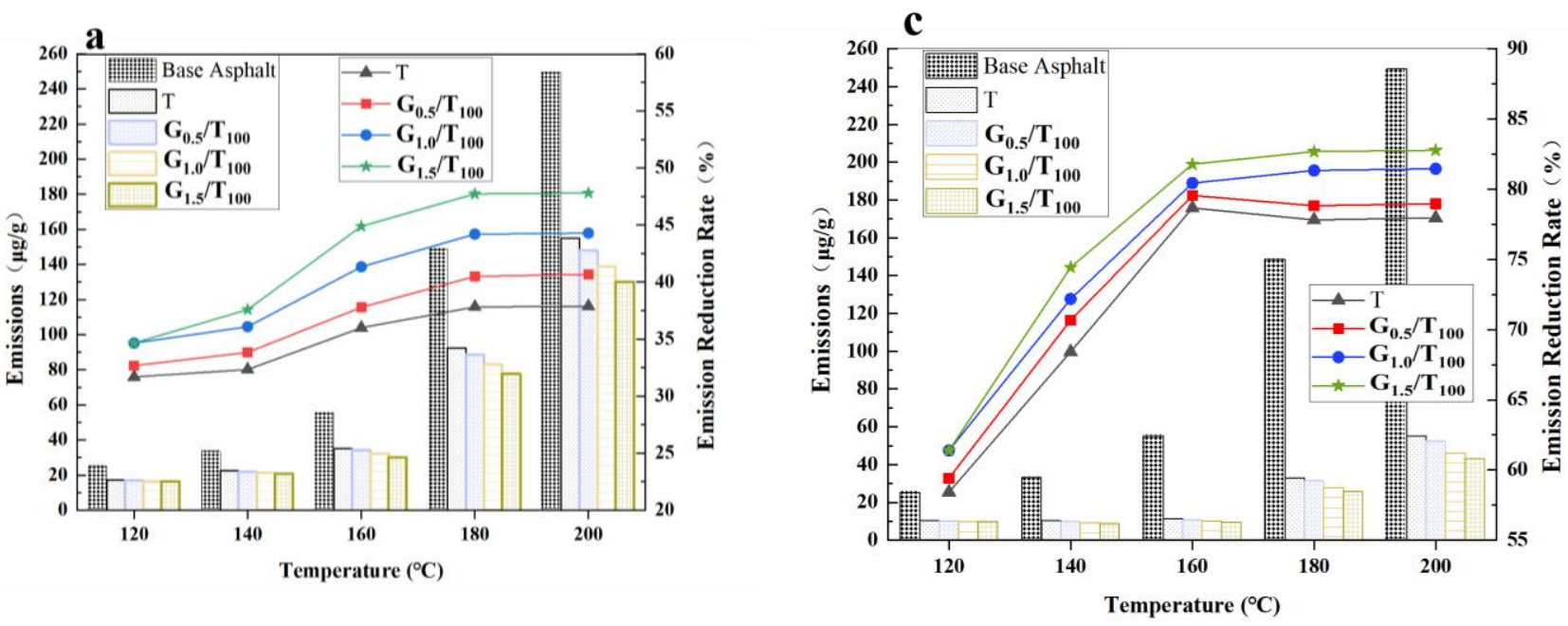

Figure 12. Asphalt fume emission reduction effect: (a) Emission reduction effect at $10 \%$ content; (b) Emission reduction effect at 20\% content; and (c) Emission reduction effect at 30\% content.

When the temperature of asphalt heating is lower than $160^{\circ} \mathrm{C}$, the emission of asphalt fumes is relatively small. It is mainly the volatilization of light components to form asphalt fumes. When the heating temperature is higher than $160^{\circ} \mathrm{C}$, the asphalt oxidation is serious. At this time, there are a lot of granular substances in the asphalt fumes. With the increase of temperature, the more that heavy components are produced, the more rapidly the asphalt fume emission increases. Adding tourmaline to asphalt can reduce the emission of asphalt fumes. The main reason is that tourmaline has a spontaneous polarization effect. The electrostatic field on the surface of tourmaline can adsorb the light components in the asphalt fumes. On the one hand, the heavy dust particles in asphalt fumes are adsorbed and settled under the action of the electrostatic field of tourmaline. On the other hand, the surface of tourmaline releases charges and contacts with the air to form negative ions, and the aromatic compounds in asphalt fumes condense and settle under the action of negative ions, thus reducing the emission of asphalt fumes. Graphene/tourmaline composites have improved the performance of asphalt fume emission reduction, mainly because the addition of graphene improves the adsorption performance and negative ion release of tourmaline, so the performance of asphalt fume emission reduction is improved. 


\subsubsection{Analysis of $\mathrm{NO}_{X}$ and $\mathrm{CO}_{X}$ Emission Reduction Effect}

A graphene/tourmaline-composite-modified asphalt mixture was prepared. According to the test method described in Section 2.4, the emission reduction effects of $\mathrm{NO}_{\mathrm{X}}$ and $\mathrm{CO}_{\mathrm{X}}$ in the mixing process of asphalt mixture with different contents of graphene/tourmaline composites were tested. The test results are shown in Table 6.

Table 6. Test results of pollutant emissions during the mixing process of graphene/tourmaline-modified asphalt mixture.

\begin{tabular}{|c|c|c|c|c|c|}
\hline \multirow[b]{2}{*}{ Mixture Type } & \multirow[b]{2}{*}{ Content $/ w t \%$} & \multicolumn{2}{|c|}{$\mathrm{NO}_{\mathbf{x}}$} & \multicolumn{2}{|c|}{$\mathrm{CO}_{\mathrm{x}}$} \\
\hline & & Concentration/ppm & $\begin{array}{c}\text { Emission } \\
\text { Reduction Rate } / \%\end{array}$ & Concentration/ppm & $\begin{array}{c}\text { Emission } \\
\text { Reduction Rate/\% }\end{array}$ \\
\hline Base Asphalt & - & 92.75 & - & 87.89 & - \\
\hline \multirow{3}{*}{$\begin{array}{l}\text { Tourmaline-modified } \\
\text { asphalt }\end{array}$} & 10 & 60.62 & 34.64 & 56.91 & 35.25 \\
\hline & 20 & 32.58 & 64.87 & 21.65 & 75.37 \\
\hline & 30 & 28.46 & 69.32 & 18.50 & 78.95 \\
\hline \multirow{3}{*}{$\begin{array}{c}\mathrm{G}_{0.5} / \mathrm{T}_{100} \text {-modified } \\
\text { asphalt }\end{array}$} & 10 & 60.32 & 34.97 & 56.24 & 36.01 \\
\hline & 20 & 32.25 & 65.23 & 21.00 & 76.11 \\
\hline & 30 & 27.66 & 70.18 & 17.95 & 79.58 \\
\hline \multirow{3}{*}{$\begin{array}{c}\mathrm{G}_{1.0} / \mathrm{T}_{100} \text {-modified } \\
\text { asphalt }\end{array}$} & 10 & 59.17 & 36.21 & 54.50 & 37.99 \\
\hline & 20 & 29.83 & 67.84 & 19.46 & 77.86 \\
\hline & 30 & 25.68 & 72.31 & 16.73 & 80.97 \\
\hline \multirow{3}{*}{$\begin{array}{c}\mathrm{G}_{1.5} / \mathrm{T}_{100} \text {-modified } \\
\text { asphalt }\end{array}$} & 10 & 59.71 & 35.62 & 55.41 & 36.95 \\
\hline & 20 & 30.63 & 66.98 & 20.31 & 76.89 \\
\hline & 30 & 26.57 & 71.35 & 17.61 & 79.96 \\
\hline
\end{tabular}

It can be seen from Table 6 that tourmaline and graphene/tourmaline composite materials have a high inhibition effect on the pollutants of $\mathrm{NO}_{X}$ and $\mathrm{CO}_{\mathrm{X}}$ produced in the mixing process of asphalt mixture, and the emission reduction rate increases with the increase of their contents. The reduction rates of $\mathrm{NO}_{X}$ and $\mathrm{CO}_{X}$ in asphalt mixing process by tourmaline are $34.64-69.32 \%$ and $35.25-78.95 \%$, respectively, and the reduction rates of $\mathrm{NO}_{X}$ and $\mathrm{CO}_{X}$ by graphene/tourmaline composites are $34.97-72.31 \%$ and $36.01-80.97 \%$, respectively. It shows that the emission reduction effect of graphene/tourmaline composite is better than that of tourmaline. The emission reduction effect of graphene/tourmaline composites first increases and then decreases with the increase of graphene content. The reason for this may be that $\mathrm{NO}_{x}$ and $\mathrm{CO}_{x}$ adsorbed by graphene surface energy re-disperse into the air under the action of mechanical force when the mixture is continuously stirred, which leads to the reduction in the emission reduction performance.

\subsection{Analysis of Modification Mechanism}

DSC tests were conducted on base asphalt, tourmaline-modified asphalt and composite modified asphalt with $\mathrm{G}_{0.5} / \mathrm{T}_{100}, \mathrm{G}_{1.0} / \mathrm{T}_{100}$ or $\mathrm{G}_{1.5} / \mathrm{T}_{100}$. The mechanism of graphene/tourmaline enhancing asphalt performance was further revealed. The area of the endothermic and exothermic peaks of the DSC curve reflects the amount of energy required for chemical or physical changes in the asphalt with temperature changes. The height and width of the endothermic and exothermic peaks indicate changes at this temperature. The glass transition temperature Tg on the DSC curve can be used to evaluate the low temperature performance of asphalt. When the asphalt is in the glassy region, the molecular chain is frozen. Only the side chain of a small unit can produce tiny vibrations around a fixed position. At this time, the asphalt is brittle, has weaker deformation resistance and is prone to cracks. Therefore, the lower the glass transition temperature of the pitch, the better the low-temperature performance of the pitch. The DSC image of each asphalt is shown in Figure 13, and the DSC image analysis results are shown in Table 7. 

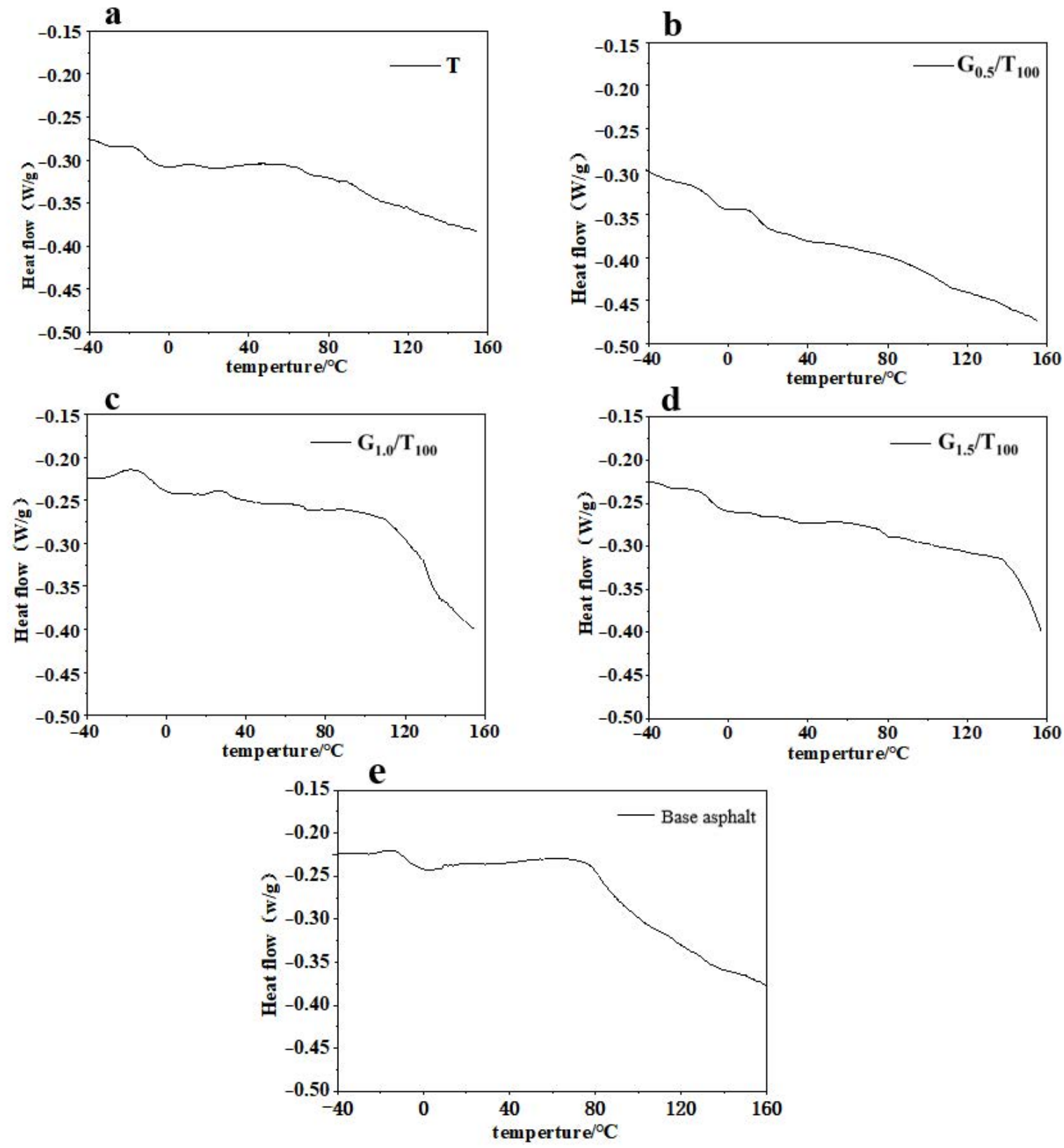

Figure 13. DSC images of graphene/tourmaline-modified asphalt: (a) T modified asphalt; (b) $\mathrm{G}_{0.5} / \mathrm{T}_{100}$ modified asphalt; (c) $\mathrm{G}_{1.0} / \mathrm{T}_{100}$ modified asphalt; (d) $\mathrm{G}_{1.5} / \mathrm{T}_{100}$ modified asphalt; and (e) Base asphalt.

Table 7. DSC image analysis results of different graphene/tourmaline-modified asphalt.

\begin{tabular}{|c|c|c|c|}
\hline Sample Information & $\begin{array}{l}\text { Heat Absorption } \\
(\mathrm{J} / \mathrm{g})\end{array}$ & Heat Release $(\mathrm{J} / \mathrm{g})$ & $\begin{array}{c}\text { Glass Transition } \\
\text { Temperature } \operatorname{Tg}\left({ }^{\circ} \mathrm{C}\right)\end{array}$ \\
\hline Base Asphalt & 0.33 & 0.36 & -9.53 \\
\hline $\begin{array}{c}\text { Tourmaline-modified } \\
\text { asphalt }\end{array}$ & 0.35 & 0.38 & -7.69 \\
\hline $\begin{array}{c}\mathrm{G}_{0.5} / \mathrm{T}_{100} \text {-modified } \\
\text { asphalt }\end{array}$ & 0.37 & 0.43 & -8.33 \\
\hline $\begin{array}{c}\mathrm{G}_{1.0} / \mathrm{T}_{100} \text {-modified } \\
\text { asphalt }\end{array}$ & 0.40 & 0.49 & -8.64 \\
\hline $\begin{array}{c}\mathrm{G}_{1.5} / \mathrm{T}_{100} \text {-modified } \\
\text { asphalt }\end{array}$ & 0.44 & 0.57 & -9.02 \\
\hline
\end{tabular}


Figure 13 and Table 7 show that the peak temperature and peak width of the endothermic and exothermic peaks of the different graphene/tourmaline-composite-modified asphalts are similar to those of tourmaline-modified asphalt and base asphalt. There is no obvious chemical change in the graphene/tourmaline-modified asphalt in the temperature range of -40 to $160^{\circ} \mathrm{C}$. Its physical and chemical state is basically consistent with that of tourmaline-modified asphalt and base asphalt.

The glass transition temperatures of tourmaline-modified asphalt and graphene/tourmaline-composite-modified asphalt are higher than that of base asphalt. However, the glass transition temperature of graphene/tourmaline-composite-modified asphalt is lower than that of tourmaline-modified asphalt. The glass transition temperature of graphene/tourmaline-composite-modified asphalt decreases with the increase of graphene content and gradually approaches that of base asphalt. Compared with the glass transition temperature of tourmaline-modified asphalt $-7.69^{\circ} \mathrm{C}$, that of composite modified asphalt with $\mathrm{G}_{0.5} / \mathrm{T}_{100}, \mathrm{G}_{1.0} / \mathrm{T}_{100}$ or $\mathrm{G}_{1.5} / \mathrm{T}_{100}$ decreases by $8.32 \%, 12.35 \%$ and $17.30 \%$, respectively. It shows that the low temperature performance of graphene/tourmaline-modified asphalt is better than that of tourmaline-modified asphalt. Analysis of the reasons for this may be that under the condition of high-temperature and high-speed shear, the molecular chain of asphalt can freely interpenetrate in the layered structure of graphene, and asphalt and graphene form a stable network structure. The addition of graphene changes the structure of asphalt and improves the flexibility of asphalt at low temperature so as to improve the low temperature crack resistance of asphalt.

The heat absorption and heat release of graphene/tourmaline-modified asphalts are higher than that of the tourmaline-modified asphalt and the base asphalt. With the increase of graphene content, the heat absorption and heat release of graphene/tourmalinecomposite-modified asphalt gradually increase, but the heat release is always greater than the heat absorption. The heat absorption and heat release of tourmaline-modified asphalt are $0.35 \mathrm{~J} / \mathrm{g}$ and $0.38 \mathrm{~J} / \mathrm{g}$, respectively. Compared with the base asphalt, the heat absorption and heat release of the $\mathrm{G}_{0.5} / \mathrm{T}_{100}$-modified asphalt increase by $12.12 \%$ and $19.44 \%$, those of the $\mathrm{G}_{1.0} / \mathrm{T}_{100}$-modified asphalt increase by $21.21 \%$ and $36.11 \%$ and those of the $\mathrm{G}_{1.5} / \mathrm{T} 100$-modified asphalt increase by $33.33 \%$ and $58.33 \%$, respectively. It indicates that the energy exchange between graphene/tourmaline-composite-modified asphalt and the external environment is greater than that of base asphalt and tourmaline-modified asphalt. So, it shows improved thermal stability and anti-aging performance. Meanwhile, the heat absorption and heat release of graphene/tourmaline-composite-modified asphalt and tourmaline-modified asphalt in the melting process are higher than that of base asphalt, and the heat absorption and heat release of graphene/tourmaline are higher than that of tourmaline-modified asphalt. For the modified asphalt system, the graphene/tourmaline composite consumes more energy when the total energy is constant, and the energy acting on the asphalt itself is relatively reduced, and the asphalt system shows better high temperature stability performance. Therefore, the high temperature stability of graphene/tourmaline-composite-modified asphalt is better than that of tourmaline-modified asphalt and base asphalt.

\section{Conclusions}

The basic performances, rheological performance and emission reduction effect of graphene/tourmaline-composite-modified asphalt were studied. The micromorphology and dispersion of graphene/tourmaline in the composite modified asphalt were clarified. In addition, the mechanisms of the modifier strengthening asphalt's performance was determined. The details are as follows.

1. The basic properties of graphene/tourmaline-composite-modified asphalt are better than those of tourmaline-modified asphalt and base asphalt, and the improvement effect is more obvious with the increase of graphene content. Compared with tourmaline-modified asphalt, the temperature susceptibility performance, high tem- 
perature stability and anti-aging performance of graphene/tourmaline-compositemodified asphalt increased by $87 \%, 8 \%$ and $58 \%$, respectively.

2. Graphene/tourmaline composites do not change the viscoelastic performance of asphalt. It improves the rutting resistance of asphalt. Compared with base asphalt, the rutting factor of composite modified asphalt is increased by 19 to $20 \%$.

3. The asphalt fume reduction effect of graphene/tourmaline-composite-modified asphalt is better than that of tourmaline-modified asphalt. With the increase of graphene content, the emission reduction performance is improved. The asphalt fume reduction rate of the composite modified asphalt can reach $83 \%$.

4. The emission reduction effect of $\mathrm{NO}_{X}$ and $\mathrm{CO}_{X}$ in the mixing process of graphene/tourmaline-composite-modified asphalt mixture is better than that of tourmaline-modified asphalt mixture, and the emission reduction rates can reach $70 \%$ and $80 \%$, respectively.

5. Compared with tourmaline-modified asphalt, the glass transition temperature of graphene/tourmaline-composite-modified asphalt decreased, and the heat absorption and heat release were higher. The thermal stability and anti-aging properties are improved.

Due to the high price of graphene, the cost of graphene/tourmaline composites is higher than the typical asphalt modifiers. The cost of graphene/tourmaline composites will limit their further promotion and application in the road field. Future research should focus on the reduction of material costs. In order to further improve the research, more testing and analysis methods of asphalt road performance should be added in the future. In addition, the components of asphalt fumes are complex and diverse. Therefore, the adsorption performance and its mechanism of each component of the modifier should be focused on.

Author Contributions: Conceptualization, T.G., C.W. and Q.C.; methodology, H.C. and Y.C.; validation, Q.W.; formal analysis, T.G.; investigation, H.F.; resources, C.W.; data curation, T.G.; writingoriginal draft preparation, T.G.; writing-review and editing, H.F.; supervision, Z.L. and A.C.; project administration, C.W. and Q.C. All authors have read and agreed to the published version of the manuscript.

Funding: This research was sponsored by the Plan for Tackling Key Problems in Science and Technology of Henan Province in 2021 (212102310089), High Level Talents Scientific Research Start Project of North China University of Water Resources and Electric Power (201811035), Fundamental Research Funds for the Central Universities (300102219314) and the Open Fund Project of Henan Province Engineering Technology Research Center for Environment-friendly and High-performance Pavement Materials (Henan Science foundation [2020] No.18).

Institutional Review Board Statement: Not applicable.

Informed Consent Statement: Not applicable.

Data Availability Statement: All data, models and code generated or used during the study appear in the published article.

Conflicts of Interest: The authors declare no conflict of interest.

\section{References}

1. Wang, C.; Wang, S.; Gao, Z.; Song, Z. Effect evaluation of road piezoelectric micro-energy collection-storage system based on laboratory and on-site tests. Appl. Energy 2021, 287, 116581. [CrossRef]

2. Fu, H.; Wang, C.; Yu, G.; Chen, Q.; Liu, L. Design optimization and performance evaluation of the open graded friction course with small particle size aggregate. Adv. Civ. Eng. 2021, 2021, 6668378.

3. Fu, H.; Wang, C.; Niu, L.; Yang, G.; Liu, L. Composition optimisation and performance evaluation of waterborne epoxy resin emulsified asphalt tack coat binder for pavement. Int. J. Pavement Eng. 2021. [CrossRef]

4. Chen, Q.; Wang, S.S.; Wang, C.H.; Wang, F.; Fu, H.; Yang, X. Modified waterborne epoxy as a cold pavement binder: Preparation and long-term working properties. J. Mater. Civ. Eng. 2021, 33, 04021079. [CrossRef]

5. Chen, Q.; Lu, Y.F.; Wang, C.H.; Han, B.; Fu, H. Effect of raw material composition on the working performance of waterborne epoxy resin for road. Int. J. Pavement Eng. 2020. [CrossRef] 
6. Wang, C.H.; Wang, P.; Li, Y.W.; Zhao, Y.Z. Laboratory investigation of dynamic rheological properties of tourmaline modified bitumen. Constr. Build. Mater. 2015, 80, 195-199. [CrossRef]

7. Vargas, M.A.; Moreno, L.; Montiel, R.; Manero, O.; Vaquez, H. Effects of montmorillonite (Mt) and two different organo-Mt additives on the performance of asphalt. Appl. Clay Sci. 2017, 139, 20-27. [CrossRef]

8. Siddig, E.A.A.; Feng, C.P.; Ming, L.Y. Effects of ethylene vinyl acetate and nanoclay additions on high-temperature performance of asphalt binders. Constr. Build. Mater. 2018, 169, 276-282. [CrossRef]

9. Liu, H.B.; Zhang, M.S.; Jiao, Y.B.; Fu, L.X. Preparation parameter analysis and optimization of sustainable asphalt binder modified by waste rubber and diatomite. Adv. Mater. Sci. Eng. 2018, 2018, 1-14. [CrossRef]

10. Liu, S.; Zhou, S.B.; Xu, Y. Evaluation of cracking properties of SBS-modified binders containing organic montmorillonite. Constr Build. Mater. 2018, 175, 196-205. [CrossRef]

11. Moghadas Nejad, F.; Azarhoosh, A.R.; Hamedi, G.H.; Azarhoosh, M.J. Characterization of permanent deformation resistance of precipitated calcium carbonate modified asphalt mixture. J. Civ. Eng. Manag. 2015, 21, 615-622. [CrossRef]

12. Liang, J.S.; Hui, N.; Zhao, T.Y.; Zhang, H. The mineralization of polymer electrospun fibrous membranes modified with tourmaline nanoparticles. J. Mater. Res. 2019, 34, 1900-1910. [CrossRef]

13. Safak, S.; Karaca, E. Production and characterization of poly(ethylene terephthalate) nanofibrous mat including tourmaline additive. Text. Res. J. 2016, 35, 258-262. [CrossRef]

14. Kim, S.J.; Ko, H.S.; Jeong, G.H.; Yun, J.J.; Park, K.H.; Han, E.M. The effect of tourmaline additives in TiOphotoanode for high-efficiency dye sensitized solar cells. Mol. Cryst. Liq. Cryst. 2016, 629, 200-205. [CrossRef]

15. García-Sánchez, T.; Muscat, A.; Leray, I.; Mir, L.M. Pyroelectricity as a possible mechanism for cell membrane permeabilization. Bioelectrochemistry 2017, 119, 227-233. [CrossRef]

16. Wang, C.H.; Chen, Q.; Guo, T.T.; Li, Q. Environmental effects and enhancement mechanism of graphene/tourmaline composites. J. Clean. Prod. 2020, 262, 121313. [CrossRef]

17. Chen, Q.; Wang, C.H.; Qiao, Z.; Guo, T.T. Graphene/tourmaline composites as a filler of hot mix asphalt mixture: Preparation and properties. Constr. Build. Mater. 2020, 239, 117859. [CrossRef]

18. Guo, T.T.; Wang, C.H.; Chen, H.J.; Li, Z.X.; Chen, Q.; Han, A.H.; Jiang, D.W.; Wang, Z.W. Rheological properties of graphenetourmaline composite modified asphalt. Pet. Sci. Technol. 2019, 37, 2190-2198. [CrossRef]

19. Wang, C.H.; Li, Y.W.; Sun, X.L.; Gao, Z.W. Automobile exhaust-purifying performance of tourmaline-modified asphalt concrete. J. Mater. Civ. Eng. 2017, 29, 04017004. [CrossRef]

20. Chen, Q.; Wang, C.H.; Wen, P.H.; Wang, M.H.; Zhao, J.X. Comprehensive performance evaluation of low-carbon modified asphalt based on efficacy coefficient method. J. Clean. Prod. 2018, 203, 633-644. [CrossRef]

21. Wu, Q.F. Study on high temperature performance of tourmaline modified asphalt mortar. Road Mach. Constr. Mech. 2017, 34, 70-74. (In Chinese)

22. Ding, H.B.; Rahman, A.; Li, Q.S.; Qiu, Y.J. Advanced mechanical characterization of asphalt mastics containing tourmaline modifier. Constr. Build. Mater. 2017, 150, 520-528. [CrossRef]

23. Rad, A.S.; Foukolaei, V.P. Density functional study of Al-doped graphene nanostructure towards adsorption of $\mathrm{CO}, \mathrm{CO}_{2}$, and $\mathrm{H}_{2} \mathrm{O}$. Synth. Met. 2015, 210, 171-178.

24. Chella, S.; Kollu, P.; Komarala, E.V.P.R.; Doshi, S.; Saranya, M.; Felix, S.; Ramachandran, R.; Saravanan, P.; Koneru, V.L.; Venugopal, $\mathrm{V}$; i et al. Solvothermal synthesis of MnFe2O4-graphene composite-Investigation of its adsorption and antimicrobial properties. Appl. Surf. Sci. 2015, 327, 27-36. [CrossRef]

25. Dervin, S.; Dionysiou, D.D.; Pillai, S.C. 2D nanostructures for water purification: Graphene and beyond. Nanoscale 2016, $8,15115$. [CrossRef]

26. Zhou, X.X.; Zhang, X.; Xu, S.; Wu, S.P.; Liu, Q.T.; Fan, Z.P. Evaluation of thermo-mechanical properties of graphene/carbonnanotubes modified asphalt with molecular simulation. Mol. Simul. 2017, 43, 312-319. [CrossRef]

27. Zhu, J.C.; Zhang, K.; Liu, K.F.; Shi, X.M. Performance of hot and warm mix asphalt mixtures enhanced by nano-sized graphene oxide. Constr. Build. Mater. 2019, 217, 273-282. [CrossRef]

28. Ingrassia, L.P.; Lu, X.; Marasteanu, M.; Canestrari, F. Tribological characterization of graphene nano-platelet (GNP) bituminous binders. In Airfield and Highway Pavements 2019: Innovation and Sustainability in Highway and Airfield Pavement Technology, Proceedings of the International Airfield and Highway Pavements Conference, Chicago, IL, USA, 21-24 July 2019; American Society of Civil Engineers: Reston, VA, USA, 2019; pp. 96-105.

29. Yan, T.; Ingrassia, L.P.; Kumar, R.; Turos, M.; Canestrari, F.; Lu, X.; Marasteanu, M. Evaluation of graphite nanoplatelets influence on the lubrication properties of asphalt binders. Materials 2020, 13, 772. [CrossRef] [PubMed]

30. Su, Z.B.; Muhammad, Y.; Sahibzada, M.; Li, J.; Zhang, L. Preparation and properties of aminated graphene fiber incorporated modified asphalt. Constr. Build. Mater. 2019, 229, 116836. [CrossRef]

31. Guo, H.Y.; Meng, Y.J.; Xu, R.G.; Zhang, R.J.; Ma, C.X. The rheological and microscopic properties of graphene rubber composite modified asphalt. J. Build. Mater. 2020, 23, 1246-1251. (In Chinese)

32. Wang, C.H.; Chen, S.; Gou, J.; Wang, X.Q.; Jiang, T.T.; Guo, T.T.; Chen, J. A Test Device for Pollutant Emission of Asphalt Mixture, ZL201420856851.1; State Intellectual Property Office: Beijing, China, 2014; pp. 1-4. (In Chinese) 